\title{
TITLE:
}

\section{Optimal monetary policy with imperfect unemployment insurance}

\author{
AUTHOR(S):
}

Nakajima, Tomoyuki

\section{CITATION:}

Nakajima, Tomoyuki. Optimal monetary policy with imperfect unemployment insurance. Journal of Economic Dynamics and Control 2010, 34(3): 365-387

\section{ISSUE DATE:}

2010-03

URL:

http://hdl.handle.net/2433/128951

\section{RIGHT:}

C 2009 Elsevier B.V.; この論文は出版社版でありません。引用の際には 出版社版をご確認ご利用ください。; This is not the published version. Please cite only the published version. 


\title{
Optimal monetary policy with imperfect unemployment insurance
}

\author{
Tomoyuki Nakajima ${ }^{a}$ \\ ${ }^{a}$ Institute of Economic Research, Kyoto University, Kyoto, Japan, and RIETI, Tokyo, Japan.
}

\begin{abstract}
We consider an efficiency-wage model with the Calvo-type sticky prices and analyze the optimal monetary policy when the unemployment insurance is not perfect. With imperfect risk sharing, the strict zero-inflation policy is no longer optimal even when the zero-inflation steady-state equilibrium is made (conditionally) efficient. Quantitative results depend on how the idiosyncratic earning loss due to unemployment varies over business cycles. If the idiosyncratic income loss is acyclical, the optimal policy differs very little from the zero-inflation policy. However, if it varies countercyclically, as evidence suggests, the deviation of the optimal policy from the complete pricelevel stabilization becomes quantitatively significant. Furthermore, the optimal policy in such a case involves stabilization of output to a much larger extent.
\end{abstract}

\section{JEL Classification: E3; E5}

Keywords: optimal monetary policy; efficiency wage; imperfect unemployment insurance; nominal rigidities.

\section{Introduction}

There is a growing literature on optimal monetary policy based on the dynamic stochastic general equilibrium framework with imperfect competition and staggered price-setting. Its simplest version has two types of distortions: relative-price distortions due to staggered price-setting and distortions associated with imperfect competition (market power). As discussed by Goodfriend and King (1997), Rotemberg and Woodford (1997) and Woodford (2003), if fiscal policy is used to offset the distortions caused by market power, then the optimal monetary policy is characterized as complete stabilization of the price level. Intuition is very simple: without distortions due to market power, the flexible-price equilibrium becomes efficient, which, in turn, can be attained by the zero-inflation policy. ${ }^{1}$ It is the price level that has to be stabilized, but not the level of output. ${ }^{2}$ As long as the inflation rate is kept at zero, any fluctuations in output would be efficient.

\footnotetext{
Email address: nakajima@kier.kyoto-u.ac.jp (Tomoyuki Nakajima)

${ }^{1}$ Note that this argument assumes that initial price dispersion is nil (or "small" if we are interested in a first-order approximation of optimal monetary policy). See Yun (2005) on this point.

${ }^{2}$ What is stabilized is the "output gap," which is defined as the difference between the actual level of output and the efficient level of output.
} 
The basic model has been extended in several directions. For instance, Benigno and Woodford (2003, 2005) and Khan, King and Wolman (2003) consider the case where distortions due to market power are present. Schmitt-Grohé and Uribe (2005) extend the analysis further, by studying a even richer model, based on Christiano, Eichenbaum and Evans (2005). The existing research on this literature, however, has restricted attention to complete-markets (representative-agent) models. In this paper we are interested to see the extent to which the nature of optimal monetary policy is affected by the presence of unemployment when unemployment insurance is not perfect. In particular, we'd like to examine whether or not the existence of imperfectly insured unemployed workers calls for more output stabilization.

For this purpose, we bring unemployment into the basic sticky-price model, building on the efficiency-wage model of Alexopoulos (2004). The model has a representative household with a continuum of individual members. In each period, each member is either employed or unemployed. An employed worker may or may not shirk. A detected shirker will be punished by an exogenous reduction in the wage payment. ${ }^{3}$ Firms determine the wage rate so that no workers would shirk in equilibrium. An important assumption that makes the model tractable is that individuals members of a household are not allowed to participate in the asset market; it is the household that makes all the decisions related to savings. Due to this assumption, we are able to use the representativehousehold framework even though the unemployment insurance is not perfect. The rest of the model is similar to the basic sticky-price model of Woodford (2003).

We analyze optimal monetary policy using the linear-quadratic approach developed by Rotemberg and Woodford (1997), Woodford (2003), and Benigno and Woodford (2003, 2005). To focus on the effect of imperfect unemployment insurance on stabilization policy, we mostly assume that fiscal policy is used to make the zero-inflation steady-state conditionally efficient. It follows that with perfect insurance the flexible-price equilibrium is efficient so that the complete price-level stabilization is the optimal policy. This is not true with imperfect insurance, so that the optimal policy would involve some fluctuations in the inflation rate. Our qualitative analysis shows that a government-purchase shock is a negative cost-push shock, while a productivity shock is a positive one. That is, optimal policy should generate some deflation (inflation) when there is an exogenous increase in government purchases (productivity).

But, quantitatively, how large is the deviation of the optimal policy from the complete pricelevel stabilization? The answer crucially depends on how idiosyncratic income shocks vary over business cycles. Specifically, what matters is how the relative income of the unemployed to that of the employed varies over business cycle. We say that idiosyncratic income losses are acyclical if the relative income of the unemployed is constant over business cycles and countercyclical if it varies procyclically. We begin with the case where the relative income of the unemployed is constant over business cycles. In this case, although the complete price-level stabilization is not exactly optimal with imperfect insurance, the optimal policy differs very little from it. Thus, as long as idiosyncratic income losses are acyclical, the optimal policy essentially takes the form of

\footnotetext{
${ }^{3}$ A relation with the model of Shapiro and Stiglitz (1984) is discussed in Appendix.
} 
the complete price-level stabilization. This is so even though the unemployment rate goes up in a recession.

Evidence seems to suggest, however, that idiosyncratic shocks are countercyclical. In particular, earning losses of unemployed or displaced workers are found to be countercyclical (e.g., Jacobson, LaLonde and Sullivan, 1993). To take it into account, our second numerical exercise assumes that the relative income of the unemployed varies procyclically over business cycles. In this case, the deviation of the optimal policy from the zero-inflation policy becomes much larger. Furthermore, the optimal policy under countercyclical idiosyncratic income losses involves stabilization of the level of output, much more so compared to the case where idiosyncratic income losses are acyclical. Intuition is simple: if a bad shock to the economy worsens uninsured idiosyncratic shocks and makes the unemployed more miserable, policy should respond to reduce the number of unemployment, which is to increase the level of output.

Our numerical exercise suggests that the mere existence of imperfectly insured unemployed workers may not justify output stabilization, for which there need to be systematic variation in the idiosyncratic risk over business cycles. An important limitation of our model is that idiosyncratic shocks are purely transitory. Evidence such as Storesletten, Telmer and Yaron (2004) suggests, however, that idiosyncratic shocks are highly persistent as well as countercyclical. Based on a nonmonetary growth model, Krebs (2007) demonstrates that the welfare cost of business cycles can be sizable with such idiosyncratic shocks. Analyzing optimal policy with persistent idiosyncratic shocks is left for future research.

This paper is organized as follows. In Section 2 the model economy is described. In Section 3 the efficient allocation and the flexible-price equilibrium are discussed. In Section 4 a linear-quadratic approximation of the model is derived. In Section 5 optimal monetary policy is examined in the case where the degree of risk sharing is constant over business cycles. Section 6 considers the case where the degree of risk sharing fluctuates cyclically. There, we also extend our analysis to the case where the non-stochastic steady state is inefficient. Concluding remarks are in Section 7.

\section{The model economy}

In this section we describe our model economy. Its key features are staggered price setting and unemployment. Our model builds on Woodford (2003) for the former and the efficiency-wage model of Alexopoulos (2004) for the latter. Alexopoulos's model differs from the well known model of Shapiro and Stiglitz (1984) in that a detected shirker is punished by a reduction in the wage rate, rather than by getting fired. Nevertheless, as discussed in Appendix, it becomes observationally equivalent to the Shapiro-Stiglitz model with a particular unemployment insurance program. Indeed, we find it very convenient that Alexopoulos's model can be made observationally equivalent to the standard indivisible-labor model of Hansen (1985) and Rogerson (1988), or to the Shapiro-Stiglitz model, depending on the assumed unemployment insurance program. 


\subsection{Households}

There is a representative household which has a continuum of individual members of unit measure. In each period, randomly selected $N_{t}$ individuals receive job offers. The rest, $1-N_{t}$, are unemployed. ${ }^{4}$ All employed workers work for a fixed length of hours, $h$. An employed worker, however, may or may not shirk. A shirker is a worker whose effort level is different from that required by her employer, $e_{t} .^{5}$

The utility flow of an employed individual who consumes $C$ and exerts an effort level $e$ is given by

$$
\mathcal{U}(C, e)=\ln C+\omega \ln (\mathcal{H}-h e),
$$

where $\omega, \mathcal{H}>0$ are constant parameters, and $C$ is the Dixit-Stiglitz aggregate of differentiated consumption goods, $c(i), i \in[0,1]$ :

$$
C=\left[\int_{0}^{1} c(i)^{\frac{\theta-1}{\theta}} d i\right]^{\frac{\theta}{\theta-1}}
$$

Given the prices of differentiated products, $p(i), i \in[0,1]$, the standard cost-minimization argument yields the price index, $P$ :

$$
P=\left[\int_{0}^{1} p(i)^{1-\theta} d i\right]^{\frac{1}{1-\theta}}
$$

and derived demand:

$$
c(i)=C\left[\frac{p(i)}{P}\right]^{-\theta}, \quad i \in[0,1] .
$$

The utility flow of an unemployed individual is given by $\mathcal{U}(C, 0)$.

An important assumption we make for tractability is that individual members of a household are not allowed to participate in the asset market (they cannot save or borrow individually). Instead, it is the household that participates in the asset market, where it trades Arrow securities for aggregate shocks with the government. ${ }^{6}$ In addition, the household receives (nominal) dividends from the firms, $\Pi_{t}(i), i \in[0,1]$; and pays (nominal) lump sum taxes to the government, $T_{t}$. The flow budget constraint of the household is then given by

$$
\mathcal{I}_{t}+E_{t}\left[Q_{t, t+1} \mathcal{A}_{t+1}\right]=\mathcal{A}_{t}+\int_{0}^{1} \Pi_{t}(i) d i-T_{t},
$$

where $\mathcal{I}_{t}$ is the "income" distributed equally across the household members, $\mathcal{A}_{t+1}$ denotes the trading in Arrow securities and $Q_{t, t+1}$ is the stochastic discount factor used to evaluate the value

\footnotetext{
${ }^{4}$ We assume that whether or not each individual receives a job offer is observable and that a person who turns down the job offer loses the eligibility for unemployment benefits. Then as long as the unemployment-insurance fee is not too large, no one would turn down a job offer.

${ }^{5}$ As we shall see, the required level of effort will be the same for all firms.

${ }^{6}$ Note that, although there is only partial insurance against idiosyncratic risk of getting unemployed, there is a complete asset market for aggregate shocks.
} 
of $\mathcal{A}_{t+1}$. We assume the natural debt limit to prevent from the Ponzi scheme:

$$
\mathcal{A}_{t+1} \geq-E_{t+1} \sum_{j=0}^{\infty} Q_{t+1, t+1+j}\left\{\int_{0}^{1} \Pi_{t+1+j}(i) d i-T_{t+1+j}\right\} .
$$

Here, $Q_{t, t+j}$ is the stochastic discount factor used to evaluate date- $t+j$ nominal income at date $t$, which is defined recursively as

$$
Q_{t, t+j}=Q_{t, t+j-1} Q_{t+j-1, t+j}, \quad j \geq 1
$$

with $Q_{t, t} \equiv 1$.

With lump-sum transfer $\mathcal{I}_{t}$ from the household, the date- $t$ consumption of an employed individual who is not detected shirking, $C_{e, t}$, is given by

$$
P_{t} C_{e, t}=\mathcal{I}_{t}+h W_{t}-\mathrm{UI}_{t}^{f}
$$

where $W_{t}$ is the nominal wage rate, and $\mathrm{UI}_{t}^{f}$ is the unemployment-insurance fee. A shirker is caught with probability $d \in(0,1)$. A detected shirker receives only a fraction $s \in[0,1)$ of the wage. Both $s$ and $d$ are constant, exogenous parameters. The date- $t$ consumption of a detected shirker, $C_{s, t}$, becomes

$$
P_{t} C_{s, t}=\mathcal{I}_{t}+s h W_{t}-\mathrm{UI}_{t}^{f}
$$

Given this, a shirker would always choose $e=0$. Finally, the level of consumption of an unemployed is given as

$$
P_{t} C_{u, t}=\mathcal{I}_{t}+\mathrm{UI}_{t}^{b}
$$

where $\mathrm{UI}_{t}^{b}$ denotes unemployment benefits. ${ }^{7}$

The objective of the household is to maximize the average utility of its members. As we shall see, firms set the wage rate, $W_{t}$, and the required level of effort, $e_{t}$, so that employed workers never shirk. Hence, the objective function of the household is given by

$$
E_{0} \sum_{t=0}^{\infty} \beta^{t}\left[N_{t} \mathcal{U}\left(C_{e, t}, e_{t}\right)+\left(1-N_{t}\right) \mathcal{U}\left(C_{u, t}, 0\right)\right]
$$

Taking as given $\mathcal{A}_{0}$ and $\left\{N_{t}, e_{t}, P_{t}, Q_{t, t+1}, T_{t}, \mathrm{UI}_{t}^{f}, \mathrm{UI}_{t}^{b}, W_{t}, \Pi_{t}(i) ; i \in[0,1], t \geq 0\right\}$, the household chooses $\left\{\mathcal{I}_{t}, \mathcal{A}_{t+1} ; t \geq 0\right\}$ so as to maximize the average utility (7) subject to (2), (3), (4), (6).

The first-order conditions imply that

$$
Q_{t, t+1} \frac{P_{t+1}}{P_{t}}=\beta \frac{N_{t+1} \mathcal{U}_{C}\left(C_{e, t+1}, e_{t+1}\right)+\left(1-N_{t+1}\right) \mathcal{U}_{C}\left(C_{u, t+1}, 0\right)}{N_{t} \mathcal{U}_{C}\left(C_{e, t}, e_{t}\right)+\left(1-N_{t}\right) \mathcal{U}_{C}\left(C_{u, t}, 0\right)}
$$

Notice that the marginal rate of substitution involves the average marginal utilities. The transversality condition takes the standard form:

$$
\lim _{j \rightarrow \infty} E_{t} Q_{t, t+j} \mathcal{A}_{t+j}=0
$$

\footnotetext{
${ }^{7}$ Our assumption that $\mathcal{I}_{t}$ is distributed equally between employed and unemployed members of the household may be justified by imposing the information restriction that individuals cannot communicate with the household after their employment status is known. I thank a referee for this interpretation.
} 


\subsection{Firms}

\subsubsection{No shirking condition}

Each differentiated product is produced by a single supplier. Each producer has the same production technology:

$$
\begin{aligned}
y_{t} & =A_{t} f\left[e_{t} h\left(n_{t}-n_{t}^{s}\right)\right], \\
& \equiv A_{t}\left[e_{t} h\left(n_{t}-n_{t}^{s}\right)\right]^{\frac{1}{\phi}},
\end{aligned}
$$

where $\phi \geq 1, A_{t}$ is the economy-wide productivity shock, $e_{t}$ is the level of effort required by the firm, $n_{t}$ and $n_{t}^{s}$ are the numbers of employed and of shirkers, respectively. Given this production technology, having shirkers would never be profitable for firms. Each firm offers an employment contract, $\left\{e_{t}, W_{t}\right\}$, to its employed. As the following argument shows, all firms offer the same contract, so that the index of firms, $i$, is omitted here.

Because a shirker is detected with probability $d$, no workers in a given firm would shirk if

$$
\mathcal{U}\left(C_{e, t}, e_{t}\right) \geq(1-d) \mathcal{U}\left(C_{e, t}, 0\right)+d \mathcal{U}\left(C_{s, t}, 0\right)
$$

Given that $C_{e, t}$ and $C_{s, t}$ are determined as in (4) and (5), the incentive-compatible level of effort must satisfy

$$
e_{t} \leq e\left(W_{t}\right) \equiv \frac{\mathcal{H}}{h}-\frac{\mathcal{H}}{h}\left(\frac{s h W_{t}+\mathcal{I}_{t}-\mathrm{UI}_{t}^{f}}{h W_{t}+\mathcal{I}_{t}-\mathrm{UI}_{t}^{f}}\right)^{\frac{d}{\omega}}
$$

where the firm take $\mathcal{I}_{t}, \mathrm{UI}_{t}^{f}$ as given.

The cost minimization problem of the firm is then given by

$$
\min _{W_{t}, n_{t}} W_{t} n_{t} \quad \text { s.t. } \quad A_{t} f\left(e_{t} h n_{t}\right) \geq y_{t}, \quad \text { and } \quad e_{t} \leq e\left(W_{t}\right) .
$$

The solution to this problem is given by

$$
\begin{aligned}
e_{t} & =e, \\
\frac{W_{t}}{P_{t}} & =\frac{\chi_{w}}{h} \frac{1}{\mathcal{U}\left(C_{e, t}, e\right)}
\end{aligned}
$$

where $e$ and $0<\chi_{w}<1$ are constants defined in Appendix. As we shall discuss below, the equilibrium wage rate in (9) is inefficient unless unemployment insurance is perfect.

\subsubsection{Calvo pricing}

The producer of product $i$ faces the demand function:

$$
y_{t}(i)=Y_{t}\left[\frac{p_{t}(i)}{P_{t}}\right]^{-\theta},
$$

where

$$
Y_{t}=\left[\int_{0}^{1} y_{t}(i)^{\frac{\theta-1}{\theta}} d i\right]^{\frac{\theta}{\theta-1}}
$$


Let $\tau$ be the tax rate on firms' revenue. The profit flow of firm $i$ is then given by

$$
\begin{aligned}
\Pi_{t}\left[p_{t}(i)\right] & =(1-\tau) p_{t}(i) y_{t}(i)-h n_{t}(i) W_{t} \\
& =(1-\tau) Y_{t} P_{t}^{\theta} p_{t}(i)^{1-\theta}-\frac{W_{t}}{e} f^{-1}\left(\frac{Y_{t} P_{t}^{\theta} p_{t}(i)^{-\theta}}{A_{t}}\right)
\end{aligned}
$$

The real marginal cost, $s_{t}(i)$, is defined by

$$
s_{t}(i)=\frac{W_{t}}{e A_{t} P_{t}} \frac{1}{f^{\prime}\left(f^{-1}\left[y_{t}(i) / A_{t}\right]\right)}
$$

Following Calvo (1983), we assume that only a fraction $(1-\alpha)$ of randomly selected firms can reset their prices in each period. The rest of firms simply charge the same prices as in the previous period. Thus, if firm $i$ receives the opportunity of resetting its product price in period $t$, it chooses $p_{t}(i)$ so as to maximize

$$
\max E_{t} \sum_{T=t}^{\infty} \alpha^{T-t} Q_{t, T} \Pi_{T}\left[p_{t}(i)\right]
$$

In this model, all firms which reset prices in the same period choose the same price. ${ }^{8}$ Let $p_{t}^{*}$ denote the price chosen by all firms resetting their prices in period $t$. It satisfies the first-order condition:

$$
E_{t} \sum_{T=t}^{\infty} \alpha^{T-t} Q_{t, T} Y_{T} P_{T}^{\theta}\left\{p_{t}^{*}-\frac{1}{1-\Phi} P_{T} s_{t, T}\right\}=0,
$$

where $s_{t, T}$ is the real marginal cost in period $T$ of those firms that reset their prices in period $t$, and

$$
\Phi \equiv 1-(1-\tau) \frac{\theta-1}{\theta}
$$

\subsection{Government}

The government conducts monetary and fiscal policy. The flow budget constraint for the government is

$$
T_{t}+\tau P_{t} Y_{t}+N_{t} \mathrm{UI}_{t}^{f}+E_{t}\left[Q_{t, t+1} \mathcal{A}_{t+1}\right]=\mathcal{A}_{t}+P_{t} G_{t}+\left(1-N_{t}\right) \mathrm{UI}_{t}^{b},
$$

where $\mathcal{A}_{t+1}$ denotes the state-contingent debt issued by the government and $\mathcal{A}_{0}$ is given.

We assume a very simple form of fiscal policy. The government takes as given $\tau, \mathrm{UI}_{t}^{f}, \mathrm{UI}_{t}^{b}, G_{t}$, as well as $P_{t}, N_{t}$, and $Y_{t}$. Fiscal policy sets $T_{t}$ in the "Ricardian" way (Woodford, 1995) so that we do not need specify the details of the conduct of fiscal policy. Monetary policy is formulated as in Woodford (2003, Chapter 7), Benigno and Woodford (2003, 2005), among others. Thus, optimal monetary policy is implicitly defined as the solution to the (adequately modified version of) Ramsey problem. With a linear-quadratic approximation, in particular, monetary policy is to set a state-contingent path of inflation rates.

\footnotetext{
${ }^{8}$ An implicit assumption here is that each firm possesses the same, constant amount of firm-specific capital. If we allow for accumulation of such capital, the price chosen by a firm would depend on the amount of capital it holds. See Woodford (2005) for such a model.
} 


\subsection{Exogenous variables}

The unemployment-insurance fee, $\mathrm{UI}_{t}^{f}$, is assumed to remain small enough that no worker with a job offer would turn it down. Specifically, given that $\mathcal{U}\left(C_{e}, e\right)=\mathcal{U}\left(C_{s}, 0\right)$ in equilibrium and that a worker who turns down a job offer is not eligible for unemployment benefits, a job offer would never be rejected if $P_{t} C_{s, t} \geq \mathcal{I}_{t}$, that is, if

$$
\mathrm{UI}_{t}^{f} \leq \operatorname{sh} W_{t},
$$

which is assumed to hold throughout this paper.

Let $B_{t}$ denote the ratio of the level of consumption of the unemployed to that of the employed:

$$
B_{t} \equiv \frac{C_{u, t}}{C_{e, t}}=\frac{\mathcal{I}_{t}+\mathrm{UI}_{t}^{b}}{h W_{t}+\mathcal{I}_{t}-\mathrm{UI}_{t}^{f}} .
$$

If unemployment insurance is perfect, $B_{t}=1$; otherwise, $B_{t}<1$. Let $C_{t}$ be the aggregate level of consumption:

$$
C_{t} \equiv N_{t} C_{e, t}+\left(1-N_{t}\right) C_{u, t}
$$

The goods-market equilibrium condition is given by

$$
Y_{t}=C_{t}+G_{t},
$$

where $G_{t}$ is government purchases. The levels of consumption of the employed and the unemployed are expressed respectively as

$$
\begin{aligned}
C_{e, t} & =\frac{1}{N_{t}+\left(1-N_{t}\right) B_{t}} C_{t}, \\
C_{u, t} & =\frac{B_{t}}{N_{t}+\left(1-N_{t}\right) B_{t}} C_{t} .
\end{aligned}
$$

The unemployment insurance program is run with balanced budget: $N_{t} \mathrm{UI}_{t}^{f}=\left(1-N_{t}\right) \mathrm{UI}_{t}^{b}$. Note that here unemployment insurance affects equilibrium only through its effect on $B_{t}$. In our benchmark analysis, we assume for simplicity that the unemployment benefits (and fees) in each period are determined so that this ratio remains constant:

$$
B_{t}=\bar{B} \in(0,1], \quad \text { for all } t .
$$

We later relax this assumption in Section 6 and let this ratio, $B_{t}$, fluctuate procyclically over time.

In the benchmark case, there are two stochastic shocks: the government-purchase shock, $G_{t}$, and the productivity shock, $A_{t}$. Assume that they take the form:

$$
G_{t}=s_{G} \bar{Y} e^{\xi_{G, t}}, \quad \text { and } \quad A_{t}=\bar{A} e^{\xi_{A, t}},
$$

where $s_{G} \in(0,1), \bar{Y}$ is the steady-state level of output, and $\left\{\xi_{G, t}, \xi_{A, t}\right\}$ follows a stationary stochastic process with unconditional mean of zero. Let $\xi_{t}$ denote the vector of these exogenous disturbances:

$$
\xi_{t}=\left(\xi_{G, t}, \xi_{A, t}\right) .
$$

When $B_{t}$ is allowed to fluctuate, we let $B_{t}=\bar{B} e^{\xi_{B, t}}$, and $\xi_{t}=\left(\xi_{G, t}, \xi_{A, t}, \xi_{B, t}\right)$. 


\section{Efficient allocation and flexible-price equilibrium}

In this section we first rewrite the household's utility in terms of aggregate output and a measure of output dispersion across firms. A key finding is that the less risk sharing is, the less concave the household's utility is in aggregate output. Then we consider the efficient allocation given the exogenous shocks: $G_{t}$ and $A_{t}$. Here, efficiency is defined conditional on that the level of effort equals the equilibrium level, $e$, and that unemployment insurance is limited by $\bar{B}$. We shall also derive the flexible-price equilibrium. It provides a useful benchmark, because, to a firstorder approximation, the level of output in the flexible-price equilibrium coincides with that in a sticky-price equilibrium with zero inflation.

\subsection{Utility flow of the household}

Using (14)-(16), the flow utility of the household (i.e., the average utility flow of its members) is given by

$$
\begin{aligned}
\mathcal{W}_{t} \equiv & N_{t} \mathcal{U}\left(C_{e, t}, e_{t}\right)+\left(1-N_{t}\right) \mathcal{U}\left(C_{u, t}, 0\right), \\
= & N_{t} \ln \left[\frac{1}{N_{t}+\left(1-N_{t}\right) B_{t}} C_{t}\right]+\left(1-N_{t}\right) \ln \left[\frac{B_{t}}{N_{t}+\left(1-N_{t}\right) B_{t}} C_{t}\right], \\
& \quad-\omega[\ln (\mathcal{H})-\ln (\mathcal{H}-h e)] N_{t}+\ln (\mathcal{H}) \\
= & \ln \left(Y_{t}-G_{t}\right)+z\left(N_{t} ; \bar{B}\right)-\omega[\ln (\mathcal{H})-\ln (\mathcal{H}-h e)] N_{t}+\ln (\mathcal{H}),
\end{aligned}
$$

where

$$
z(N ; B) \equiv(1-N) \ln B-\ln [N+(1-N) B] .
$$

The function $z(N ; B)$ represents the inefficiency caused by imperfect risk sharing, $B$. If $B=1$, $z(N ; 1)=0$ for all $N$, so that the flow utility of the household takes the same form as in the indivisible labor model of Hansen (1985) and Rogerson (1988):

$$
\mathcal{W}_{t}=\ln \left(Y_{t}-G_{t}\right)-\omega[\ln (\mathcal{H})-\ln (\mathcal{H}-h e)] N_{t}+\ln (\mathcal{H}) .
$$

When $B<1, z(N ; B)$ has a minimum at $N=\underline{N}(B)$, where

$$
\underline{N}(B) \equiv \frac{1-B+B \ln (B)}{-(1-B) \ln (B)}<\frac{1}{2}
$$

and is increasing in $N$ for $N>\underline{N}(B)$ and decreasing in $N$ for $N<\underline{N}(B)$. In what follows, we focus on the case where $N_{t}>1 / 2$ holds almost surely for all $t$. Note also that the function $z(N ; B)$ is convex in $N$. Therefore, imperfect risk sharing makes the household's objective function less concave.

The aggregate employment, $N_{t}$, is expressed as

$$
\begin{aligned}
N_{t} & =\int_{0}^{1} n_{t}(i) d i=\int_{0}^{1} \frac{1}{e h}\left[\frac{y_{t}(i)}{A_{t}}\right]^{\phi} d i, \\
& =\frac{1}{e h}\left(\frac{Y_{t}}{A_{t}}\right)^{\phi} \Delta_{t}, \\
& \equiv N\left(Y_{t}, \Delta_{t} ; A_{t}\right),
\end{aligned}
$$


where $\Delta_{t}$ is the output (or price) dispersion measure defined as

$$
\Delta_{t} \equiv \int_{0}^{1}\left[\frac{y_{t}(i)}{Y_{t}}\right]^{\phi} d i=\int_{0}^{1}\left[\frac{p_{t}(i)}{P_{t}}\right]^{-\theta \phi} d i \geq 1
$$

where the inequality follows from Jensen's inequality.

Using this, the flow utility of the household can be expressed as a function of $Y_{t}, \Delta_{t}$, and exogenous disturbances:

$$
\mathcal{W}\left(Y_{t}, \Delta_{t} ; \xi_{t}\right)=U\left(Y_{t} ; G_{t}\right)+Z\left(Y_{t}, \Delta ; A_{t}, \bar{B}\right)-V\left(Y_{t}, \Delta_{t} ; A_{t}\right)+\ln (\mathcal{H})
$$

where

$$
\begin{aligned}
U(Y ; G) & \equiv \ln (Y-G), \\
Z(Y, \Delta ; A, B) & \equiv z[N(Y, \Delta ; A) ; B], \\
V(Y, \Delta ; A) & =\omega[\ln (\mathcal{H})-\ln (\mathcal{H}-h e)] N(Y, \Delta ; A)
\end{aligned}
$$

Since $N(Y, \Delta ; A)$ is convex in $Y$, so is $Z(Y, \Delta ; A, B)$. Hence imperfect unemployment insurance, $\bar{B}<1$, makes the objective function of the household less concave relative to the case of perfect insurance. That is, ceteris paribus, the household tends to be willing to accept larger fluctuations in output when risk sharing is not perfect. This property plays an important role in determining the character of optimal monetary policy in our model. Throughout this paper we assume that $Z(Y, \Delta ; A, B)$ is not so convex that $\mathcal{W}(Y, \Delta ; \xi)$ is strictly concave in $Y$ and $\Delta$ for each $\xi$.

Assumption 1. For each $\xi, \mathcal{W}(Y, \Delta ; \xi)$ is strictly concave in $Y$ and $\Delta$.

\subsection{Efficient rate of output}

The efficient allocation is the feasible allocation that maximizes the expected discounted sum of the household's average utility flows, $\left\{\mathcal{W}_{t}\right\}$, in $(20)$. This Pareto problem has no predetermined variables and can be solved state by state in a static fashion. For each $\xi_{t}$, the efficient allocation, $\left\{y_{t}^{*}(i): i \in[0,1]\right\}$, is the solution to

$$
\max _{\left\{y_{t}(i)\right\}} \mathcal{W}\left(Y_{t}, \Delta_{t} ; \xi_{t}\right)
$$

where $Y_{t}$ is given by (11). Under our assumption, it is straightforward to see that there is no output dispersion in the efficient allocation:

$$
y_{t}^{*}(i)=Y_{t}^{*}, \quad \text { and } \quad \Delta_{t}^{*}=1,
$$

and that the efficient level of aggregate output satisfies the first-order condition:

$$
U_{Y}\left(Y_{t}^{*} ; G_{t}\right)+Z_{Y}\left(Y_{t}^{*}, 1 ; A_{t}, \bar{B}\right)=V_{Y}\left(Y_{t}^{*}, 1 ; A_{t}\right) .
$$

As shown in Appendix, the efficient level of output is decreasing in the level of risk sharing, $\bar{B}$ :

$$
\frac{\partial Y_{t}^{*}}{\partial \bar{B}} \leq 0
$$

Thus lower risk sharing (lower $\bar{B}$ ) raises the efficient level of output. This is because less risk sharing makes unemployment more costly, and hence the efficient level of unemployment is lower, which implies that the efficient level of output is higher. 


\subsection{Flexible price equilibrium}

Here we consider the flexible-price equilibrium, in which each firm can change its product price freely in every period. The flexible-price equilibrium defines the "natural rates" of endogenous variables, which are denoted by superscript $n$.

With flexible prices, each firm $i \in[0,1]$ chooses $p_{t}(i)$ so that

$$
\frac{p_{t}(i)}{P_{t}}=\frac{1}{1-\Phi} s_{t}(i)
$$

In the symmetric equilibrium, all firms charge the same price, $p_{t}(i)=P_{t}$, which yields

$$
s_{t}(i)=1-\Phi, \quad \forall i \in[0,1] .
$$

In the flexible-price equilibrium, consumption of the employed can be written as

$$
C_{e, t}^{n}=D\left(Y_{t}^{n} ; A_{t}, \bar{B}\right)\left(Y_{t}^{n}-G_{t}\right),
$$

where

$$
D(Y ; A, B) \equiv \frac{1}{N(Y, 1 ; A)+[1-N(Y, 1 ; A)] B} .
$$

Using (9), (21) and (23), condition (26) can be expressed as

$$
\chi(1-\Phi) U_{Y}\left(Y_{t}^{n} ; G_{t}\right) D\left(Y_{t}^{n} ; A_{t}, \bar{B}\right)^{-1}=V_{Y}\left(Y_{t}^{n}, 1 ; A_{t}\right),
$$

where $\chi$ is the constant defined by

$$
\chi \equiv \frac{\omega[\ln (\mathcal{H})-\ln (\mathcal{H}-h e)]}{\chi_{w}}
$$

The natural rate of output, $Y_{t}^{n}$, is defined implicitly in (27).

As shown in Appendix, in contrast with the case of the efficient rate of output (25), the natural rate of output increases with the level of risk sharing:

$$
\frac{\partial Y_{t}^{n}}{\partial \bar{B}} \geq 0
$$

This is because, other things being equal, an increase in risk sharing tends to reduce the amount of consumption of the employed due to a rise in the unemployment-insurance fee. As shown in equation (9), a decline in consumption of the employed, in turn, lowers the wage rate and hence increases production.

\section{Linear-quadratic approximation}

We wish to characterize the optimal monetary policy using the linear-quadratic approach developed by Woodford (2003) and Benigno and Woodford (2003, 2005). In that approach, the monetary authority maximizes a quadratic approximation of the utility of the representative household subject to a log-linear approximation of the aggregate supply relation. Each approximation is taken around the zero-inflation steady state. 
With the Calvo pricing, the price index, $P_{t}$, evolves as

$$
P_{t}=\left[(1-\alpha) p_{t}^{* 1-\theta}+\alpha P_{t-1}^{1-\theta}\right]^{\frac{1}{1-\theta}},
$$

where $p_{t}^{*}$ is the newly set price in period $t$, defined in (13). It follows that

$$
\frac{p_{t}^{*}}{P_{t}}=\left(\frac{1-\alpha \Pi_{t}^{\theta-1}}{1-\alpha}\right)^{\frac{1}{1-\theta}}
$$

where $\Pi_{t} \equiv P_{t} / P_{t-1}$ is the gross rate of inflation in period $t$. Similarly, the evolution of the price dispersion measure, $\Delta_{t}$, is given by

$$
\begin{aligned}
\Delta_{t} & =\int_{0}^{1}\left[\frac{p_{t}(i)}{P_{t}}\right]^{-\theta \phi} d i \\
& =(1-\alpha)\left(\frac{p_{t}^{*}}{P_{t}}\right)^{-\theta \phi}+\alpha \Pi_{t}^{\theta \phi} \Delta_{t-1}
\end{aligned}
$$

Using (30), we obtain

$$
\Delta_{t}=(1-\alpha)\left(\frac{1-\alpha \Pi_{t}^{\theta-1}}{1-\alpha}\right)^{\frac{\theta \phi}{\theta-1}}+\alpha \Pi_{t}^{\theta \phi} \Delta_{t-1}
$$

Consider the zero-inflation steady state, that is, the equilibrium in which $\xi_{t}=0$ and $\Pi_{t}=1$, for all $t$. In what follows, the value of each variable at the zero-inflation steady state is denoted by a bar. Equation (31) implies that $\Delta_{t}=1$, all $t$. The first-order condition (13) reduces to $s_{t}(i)=1-\Phi$, for all $i$, which implies that the level of output at the zero-inflation steady state, $\bar{Y}$, is the solution to

$$
\chi(1-\Phi) U_{Y}(\bar{Y} ; \bar{G}) D(\bar{Y} ; \bar{A}, \bar{B})^{-1}=V_{Y}(\bar{Y}, 1 ; \bar{A})
$$

We assume that the zero-inflation steady-state equilibrium is (conditionally) efficient.

Assumption 2. The tax rate on monopoly revenue, $\tau$, is set so that the level of output in the zero-inflation steady state is efficient:

$$
\bar{Y}=\bar{Y}^{*}
$$

Whether or not unemployment insurance is perfect, imperfect competition would cause inefficiency at the steady state. How such inefficiency affects the optimal equilibrium path has been analyzed, for instance, by Khan, King and Wolman (2003) and Benigno and Woodford (2003, 2005). With Assumption 2, we can focus on the inefficiency that imperfect unemployment insurance introduces outside the steady state.

As shown in Appendix, a log-linear approximation of first-order condition (13) for $p_{t}^{*}$ is given by

$$
\pi_{t}=\kappa x_{t}+\beta E_{t} \pi_{t+1}+u_{t} .
$$


Here $x_{t}$ is the (welfare-relevant) output gap:

$$
x_{t} \equiv \hat{Y}_{t}-\hat{Y}_{t}^{*}
$$

$u_{t}$ is the "cost-push shock," defined by

$$
u_{t} \equiv \kappa\left(\hat{Y}_{t}^{*}-\hat{Y}_{t}^{n}\right)
$$

and $\kappa$ is the constant defined by

$$
\kappa \equiv \frac{(1-\alpha)(1-\alpha \beta)}{\alpha} \frac{\sigma^{-1}-\delta+\phi-1}{1+(\phi-1) \theta},
$$

where $\sigma^{-1}$ and $\delta$ are the elasticities of $U_{Y}$ and $D^{-1}$ with respect to $Y$ evaluated at the zero-inflation steady state:

$$
\sigma^{-1} \equiv-\frac{U_{Y Y} \bar{Y}}{U_{Y}}=\frac{1}{1-s_{G}}>1, \quad \delta \equiv-\frac{D_{Y} \bar{Y}}{D}=\frac{(1-\bar{B}) \bar{N}}{\bar{N}+(1-\bar{N}) \bar{B}} \geq 0 .
$$

Note that $\delta=0$ with perfect insurance. It immediately follows that imperfect insurance makes $\kappa$ smaller. In other words, the real effect of a nominal shock is larger with imperfect insurance.

Proposition 1. Imperfect insurance makes the coefficient $\kappa$ in the AS relation (32) smaller:

$$
\left.\kappa\right|_{\bar{B}<1}<\left.\kappa\right|_{\bar{B}=1} .
$$

Also as shown in Appendix, a quadratic approximation of the household's utility is given by

$$
E_{0} \sum_{t=0}^{\infty} \beta^{t} \mathcal{W}_{t}=-\bar{Y} V_{Y} E_{0} \sum_{t=0}^{\infty} \beta^{t} \frac{1}{2}\left[q_{\pi} \pi_{t}^{2}+q_{y} x_{t}^{2}\right]
$$

where

$$
\begin{aligned}
& q_{\pi} \equiv \frac{\alpha \theta[1+(\phi-1) \theta]}{(1-\alpha)(1-\alpha \beta)}(1-\Gamma), \\
& q_{y} \equiv \sigma^{-1}(1-\Gamma)-\zeta \Gamma+\phi-1 .
\end{aligned}
$$

Here, $\zeta$ and $\Gamma$ are constants defined by

$$
\zeta \equiv \frac{Z_{Y Y} \bar{Y}}{Z_{Y}} \geq 0, \quad \Gamma \equiv \frac{Z_{Y}}{U_{Y}+Z_{Y}} \in[0,1]
$$

where all derivatives are evaluated at the zero-inflation steady state. From (32) and (33), it follows that the exogenous shocks relevant for the optimal policy problem are summarized into a single composite variable, $u_{t}$.

\section{Optimal policy with constant risk sharing}

In the traditional (Ramsey) approach, the optimal policy problem, say at date $t_{0}$, is to choose a state-contingent path, $\left\{\pi_{t}, x_{t}\right\}_{t \geq t_{0}}$, so as to maximize the household's utility (33) subject to the 
aggregate-supply relation (32) for $t \geq t_{0}$. As is well known, this type of optimization fails to be time consistent: if the planner is allowed to reoptimize at a future date, it will choose a different path of inflation and output gap. Concerning this issue, Woodford (2003) and Benigno and Woodford $(2003,2005)$ have shown that the optimal policy problem can be modified into a recursive form with an additional constraint, which is to allow the planner to make a commitment for one period. The solution to such a constrained policy problem is called optimal policy from a timeless perspective. Specifically, in the linear-quadratic problem here, the modified policy problem at any date $t_{0}$ is to choose a state-contingent path, $\left\{\pi_{t}, x_{t}\right\}_{t \geq t_{0}}$, so as to maximize the household's utility subject to the aggregate-supply relation as well as to the commitment from the previous period of the form:

$$
\pi_{t_{0}}=\bar{\pi}_{t_{0}}
$$

Following Woodford (2003) and others, we shall consider the policy problem constrained in this fashion. Note, however, that it yields the same impulse responses to exogenous disturbances as the traditional, unconstrained policy problem (Woodford, 2003, Proposition 7.9).

Letting $\varphi_{t}$ be the Lagrange multiplier for (32), the first-order conditions yield

$$
\begin{aligned}
\pi_{t} & =\frac{1}{q_{\pi}}\left(\varphi_{t-1}-\varphi_{t}\right), \\
x_{t} & =\frac{\kappa}{q_{y}} \varphi_{t} .
\end{aligned}
$$

Substituting into (32), we obtain the second-order difference equation in $\varphi_{t}$ :

$$
\beta q_{y} E_{t} \varphi_{t+1}-\left[(1+\beta) q_{y}+\kappa^{2} q_{\pi}\right] \varphi_{t}+q_{y} \varphi_{t-1}=q_{\pi} q_{y} u_{t}
$$

Its characteristic equation,

$$
\beta q_{y} \mu^{2}-\left[(1+\beta) q_{y}+\kappa^{2} q_{\pi}\right] \mu+q_{y}=0
$$

has a solution pair, $\mu \in(0,1)$ and $1 /(\beta \mu)>1$. It follows that a bounded solution to (36) takes the form of

$$
\varphi_{t}=\mu \varphi_{t-1}-q_{\pi} \sum_{j=0}^{\infty} \beta^{j} \mu^{j+1} E_{t} u_{t+j}
$$

where $\varphi_{t_{0}-1}$ satisfies the initial condition: $\varphi_{t_{0}-1}-\varphi_{t_{0}}=q_{\pi} \bar{\pi}_{t_{0}}$. Given $\left\{\varphi_{t}\right\}$, the optimal statecontingent evolution of $\pi_{t}$ and $x_{t}$ are derived using (34)-(35).

Equations (34), (35) and (37) tell us how the optimal state-contingent paths of $\pi_{t}$ and $x_{t}$ depend on the composite shock, $u_{t}=\kappa\left(\hat{Y}_{t}^{*}-\hat{Y}_{t}^{n}\right)$. For example, consider impulse responses to a cost-push shock in period $t$. To be specific, suppose that $u_{t}$ follows an $\operatorname{AR}(1)$ process given by $u_{t}=\rho_{u} u_{t-1}+\epsilon_{u, t}$ where $\rho_{u} \in(-1,1)$ and $\epsilon_{u, t}$ is i.i.d. with zero mean. Equation (37) implies that

$$
\varphi_{t+j}=\mu \varphi_{t+j-1}+\phi_{u} u_{t+j}
$$


where $\phi_{u} \equiv-\mu q_{\pi} /\left(1-\beta \mu \rho_{u}\right)$. It follows that impulse responses at dates $t+j, j=0,1, \ldots$, become

$$
\begin{aligned}
E_{t} \varphi_{t+j}-E_{t-1} \varphi_{t+j} & =\frac{\mu^{j+1}-\rho_{u}^{j+1}}{\mu-\rho_{u}} \phi_{u} \epsilon_{u, t} \\
E_{t} x_{t+j}-E_{t-1} x_{t+j} & =\frac{\kappa}{q_{y}} \frac{\mu^{j+1}-\rho_{u}^{j+1}}{\mu-\rho_{u}} \phi_{u} \epsilon_{u, t} \\
E_{t} p_{t+j}-E_{t-1} p_{t+j} & =-\frac{1}{q_{\pi}} \frac{\mu^{j+1}-\rho_{u}^{j+1}}{\mu-\rho_{u}} \phi_{u} \epsilon_{u, t}
\end{aligned}
$$

and

$$
E_{t} \pi_{t+j}-E_{t-1} \pi_{t+j}= \begin{cases}-\frac{1}{q_{\pi}} \phi_{u} \epsilon_{u, t}, & \text { for } j=0 \\ \frac{1}{q_{\pi}} \frac{\mu^{j}(1-\mu)-\rho_{u}^{j}\left(1-\rho_{u}\right)}{\mu-\rho_{u}} \phi_{u} \epsilon_{u, t}, & \text { for } j \geq 1\end{cases}
$$

To see now how $u_{t}$ depends on the fundamental shocks, log-linearize the first-order conditions (24) and (27) around the zero-inflation steady state:

$$
\begin{aligned}
& \hat{Y}_{t}^{*}=c_{A}^{*} \xi_{A, t}+c_{G}^{*} \xi_{G, t} \\
& \hat{Y}_{t}^{n}=c_{A}^{n} \xi_{A, t}+c_{G}^{n} \xi_{G, t}
\end{aligned}
$$

where $^{9}$

$$
\begin{aligned}
c_{A}^{*} & \equiv \frac{\phi-\Gamma(\zeta+1)}{\sigma^{-1}(1-\Gamma)-\zeta \Gamma+\phi-1} \\
c_{G}^{*} & \equiv \frac{\sigma^{-1}(1-\Gamma) s_{G}}{\sigma^{-1}(1-\Gamma)-\zeta \Gamma+\phi-1}>0 \\
c_{A}^{n} & \equiv \frac{\phi-\delta}{\sigma^{-1}-\delta+\phi-1}>0 \\
c_{G}^{n} & \equiv \frac{\sigma^{-1} s_{G}}{\sigma^{-1}-\delta+\phi-1}>0
\end{aligned}
$$

Given this, we can express the cost push shock as

$$
u_{t}=c_{A}^{u} \xi_{A, t}+c_{G}^{u} \xi_{G, t},
$$

where $c_{s}^{u} \equiv \kappa\left(c_{s}^{*}-c_{s}^{n}\right)$, for $s=A, G$.

\subsection{Effects of imperfect insurance: Theoretical results}

Optimal policy involves strict price-level stabilization (zero inflation), if the flexible-price equilibrium is optimal so that $\hat{Y}_{t}^{n}=\hat{Y}_{t}^{*}$ and $u_{t}=0$. It is obviously the case when the unemployment insurance is perfect: $\bar{B}=1$. It is also the case when there are no government purchases in the steady state, $s_{G}=0$. This is due to our homothetic preferences, as is discussed in Benigno and Woodford (2005). The following proposition summarizes.

\footnotetext{
${ }^{9}$ If inequality (44) below holds, $c_{A}^{*}>0$.
} 
Proposition 2. (a) If $\bar{B}=1$, then $c_{A}^{*}=c_{A}^{n}$ and $c_{G}^{*}=c_{G}^{n}$. (b) If $s_{G}=0$, then $c_{A}^{*}=c_{A}^{n}$.

In general, the flexible-price equilibrium is not efficient outside the steady state, that is, $Y_{t}^{n} \neq$ $Y_{t}^{*}$, in spite of Assumption 2. Given the first-order conditions (24) and (27), the elasticities of $U_{Y}+Z_{Y}$ and $U_{Y} D^{-1}$ with respect to $Y$ are important in determining the nature of optimal monetary policy. At the zero-inflation steady state, those elasticities are given by

$$
\begin{aligned}
& -\frac{U_{Y Y} Y+Z_{Y Y} Y}{U_{Y}+Z_{Y}}=\sigma^{-1}(1-\Gamma)-\zeta \Gamma \leq \sigma^{-1} \\
& -\frac{U_{Y Y} Y}{U_{Y}}+\frac{D_{Y} Y}{D}=\sigma^{-1}-\delta \leq \sigma^{-1}
\end{aligned}
$$

With $\bar{B}=1$, they are both equal to $\sigma^{-1}$ since $\delta=\Gamma=0$. Thus, imperfect insurance makes both $U_{Y}+Z_{Y}$ and $U_{Y} D^{-1}$ less elastic with respect to $Y$. The former follows from the fact that imperfect insurance makes the aggregate utility less concave. The latter follows from the fact that an increase in $Y$ raises $C_{e}$ less than $C$, because it reduces unemployment (this effect is reflected in the term $D^{-1}$ ). As the next proposition states, this property implies that the response of $Y_{t}^{*}$ and $Y_{t}^{n}$ to an exogenous shift in $G_{t}$ is larger with imperfect insurance than with perfect insurance.

Proposition 3. Assume that $s_{G}>0$. The responses of $Y_{t}^{*}$ and $Y_{t}^{n}$ to $G_{t}$ are larger with imperfect insurance than with perfect insurance:

$$
\begin{gathered}
\left.c_{G}^{*}\right|_{\bar{B}=1}<\left.c_{G}^{*}\right|_{\bar{B}<1}, \\
\left.c_{G}^{n}\right|_{\bar{B}=1}<\left.c_{G}^{n}\right|_{\bar{B}<1} .
\end{gathered}
$$

In other words, imperfect insurance makes the efficient and natural rates of output more volatile in response to a "demand shock." The opposite is true for the response to a "supply shock," $A_{t}$.

Proposition 4. Assume that $s_{G}>0$. The responses of $Y_{t}^{*}$ and $Y_{t}^{n}$ to $A_{t}$ are smaller with imperfect insurance than with perfect insurance:

$$
\begin{aligned}
& \left.c_{A}^{*}\right|_{\bar{B}<1}<\left.c_{A}^{*}\right|_{\bar{B}=1}, \\
& \left.c_{A}^{n}\right|_{\bar{B}<1}<\left.c_{A}^{n}\right|_{\bar{B}=1} .
\end{aligned}
$$

With perfect insurance, the efficient (and the natural) rate of output is determined by the equation $U_{Y}=V_{Y}$, where the left-hand side expresses the marginal benefit of increasing $Y$ and the right-hand side its marginal cost. An increase in productivity, $A$, lowers the marginal cost but does not affect the marginal benefit, and hence raises the efficient rate of output. With imperfect insurance, this effect is partially offset because $A$ lowers $Z_{Y}$ and $D^{-1}$.

Whether $G$ and $A$ are positive or negative cost push shocks depends on the elasticities of $U_{Y}+Z_{Y}$ and $U_{Y} D^{-1}$. The following lemma provides a necessary and sufficient condition that the former is greater than the latter.

\section{Lemma 1.}

$$
\sigma^{-1}(1-\Gamma)-\zeta \Gamma>\sigma^{-1}-\delta>0
$$


if and only if $\sigma^{-1}-\delta>0$ and

$$
\left(\sigma^{-1}-\delta\right)[2 \delta+\ln (\bar{B}) N \phi]>(\phi-1)[-\ln (\bar{B}) N \phi-\delta]
$$

Condition (44) holds if $\phi=1$ and $\bar{B} \in(0.21,1)$. Indeed, it is satisfied for all the numerical exercises we have considered, and hence, we shall restrict our attention to such a case.

Proposition 5. Assume that $s_{G}>0, \bar{B}<1$ and (44) holds. Then the government-purchase shock, $G$, is a negative cost-push shock and the productivity shock, $A$, is a positive cost-push shock:

$$
c_{G}^{u}<0, \quad \text { and } \quad c_{A}^{u}>0 .
$$

The following proposition shows how imperfect insurance affects the persistence parameter $\mu$ of optimal policy.

Proposition 6. Under condition (44), imperfect insurance makes the persistence parameter $\mu$ in (37) larger:

$$
\left.\mu\right|_{\bar{B}=1}<\left.\mu\right|_{\bar{B}<1} .
$$

\subsection{Effects of imperfect insurance: Quantitative results}

We have seen that the exact zero-inflation policy is not optimal if the unemployment insurance is not perfect. Here we examine quantitatively how much optimal policy differs from the complete price-level stabilization. Assume that the exogenous disturbances, $\xi_{A, t}$ and $\xi_{G, t}$, follow the $\operatorname{AR}(1)$ process given by $\xi_{A, t}=\rho_{A} \xi_{A, t-1}+\epsilon_{A, t}$ and $\xi_{G, t}=\rho_{G} \xi_{G, t-1}+\epsilon_{G, t}$, where $\epsilon_{A, t}$ and $\epsilon_{G, t}$ are i.i.d. random variables with mean zero. In the numerical exercise below, we set $\alpha=0.66, \beta=0.99$ (the time unit is a quarter), $\phi=1.47, \theta=10$, which are in accordance with the parameter values assumed in Woodford (2003, Table 5.1). In addition we assume $s_{G}=0.2$ and $\bar{N}=0.94$. Different values are examined for $\bar{B}, \rho_{A}$ and $\rho_{G}$.

Figures 1-4 plot optimal responses of $\pi_{t}, x_{t} \equiv \hat{Y}_{t}-\hat{Y}_{t}^{*}$, and $\hat{Y}_{t}$ to the productivity and government-purchase shocks, for different values of $\bar{B}, \rho_{A}$, and $\rho_{G} \cdot{ }^{10}$ We set the size of the initial innovation to the two shocks as $\epsilon_{A, 0}=-2.34 \%$ and $\epsilon_{G, 0}=-13.76 \%$, both of which reduce the efficient level of output by 2 percent, $\hat{Y}_{0}^{*}=-2 \%$, in the case of $\bar{B}=1$ and $\rho_{A}=\rho_{G}=0$. The inflation rate is expressed as an annual rate in percentage points and the output gap and the level of output are expressed in percentage deviations from their steady state values.

***Figures 1-2 are around here. ${ }^{* * *}$

In Figures 1-2, shocks are serially uncorrelated, $\rho_{A}=\rho_{G}=0$, and different degrees of risk sharing are considered: $\bar{B}=0.5,0.75,1.0$. Consistent with the theoretical results above, the

\footnotetext{
${ }^{10}$ Specifically, those figures plot $E_{0} \pi_{t}-E_{-1} \pi_{t}$ etc. for $t=0,1, \ldots, 8$.
} 
exact price stabilization is optimal in the case of perfect insurance $(\bar{B}=1)$, and the less risk sharing is (the lower $\bar{B}$ is), the more the optimal policy differs from the complete price-level stabilization. Consistent with Propositions 3-4, less insurance makes optimal responses of output to the government-purchase shock (the productivity shock) larger (smaller). However, quantitatively, the optimal policy may not be distinguishable from the complete price-level stabilization. Figures 1-2 show that even when $\bar{B}$ is as low as 0.5 , the optimal policy generates almost no inflation or deflation and lets output decline by about 2 percent.

***Figures 3-4 are around here. ${ }^{* * *}$

We have seen that, quantitatively, the steady-state level of risk sharing, $\bar{B}$, does not matter much. In what follows we set our benchmark value of $\bar{B}$ to 0.75 . We have chosen this value following Alexopoulos (2004), who set $\bar{B}=0.78$ based on the evidence in Gruber (1997). ${ }^{11}$ We next examine the effects of the persistence of each shock. In Figures 3-4, we plot the optimal policy responses when $\rho_{A}$ and $\rho_{G}$ are 0.9 , respectively $(\bar{B}=0.75)$. As the persistence of a shock becomes greater, the optimal responses to it involve larger fluctuations in the inflation rate and the output gap. However, these figures show again that, regardless of the values of $\rho_{A}$ and $\rho_{G}$, deviations of the optimal policy from the complete price-level stabilization is quantitatively very small. We thus conclude that, as far as the degree of risk sharing is constant, imperfect risk sharing does not have quantitatively significant impact on the optimal policy, and the optimal policy is essentially characterized by the price-level stabilization.

\section{Optimal policy with countercyclical idiosyncratic shocks}

We have so far focused on the case where the degree of risk sharing is constant, $B_{t}=\bar{B}$. In our model, $B_{t}$ is the relative income level of the unemployed to the employed, and hence, it measures the earning loss that workers experience when they get unemployed. According to the evidence such as Jacobson, LaLonde and Sullivan (1993), such earning loss fluctuates countercyclically, i.e., $B_{t}$ fluctuates procyclically. ${ }^{12}$ In this section we shall see that the optimal policy would involve much larger fluctuations in inflation if $B_{t}$ fluctuates procyclically.

\footnotetext{
${ }^{11}$ Although $\bar{B}$ does not matter much in our model, it may well play an important role in other contexts. For instance, the results by Shimer (2005) and Hagedorn and Manovskii (2008) show that the value of non-market activity, which might correspond to $\bar{B}$ in our model, significantly affects the cyclical properties of the labor search model. Hagedorn and Manovskii show that the standard search model does much better if we set $\bar{B}=0.95$, as opposed to the value chosen by Shimer (2005), which is, $\bar{B}=0.4$.

${ }^{12}$ More broadly, Storesletten, Telmer and Yaron (2004) show evidence that the idiosyncratic income risk fluctuates countercyclically.
} 


\subsection{Optimal responses to a negative insurance shock}

With time-varying $B_{t}=\bar{B} \exp \left(\xi_{B, t}\right)$, the efficient and the natural rates of output are given, respectively, as

$$
\begin{aligned}
& \hat{Y}_{t}^{*}=c_{A}^{*} \xi_{A, t}+c_{G}^{*} \xi_{G, t}+c_{B}^{*} \xi_{B, t} \\
& \hat{Y}_{t}^{n}=c_{A}^{n} \xi_{A, t}+c_{G}^{n} \xi_{G, t}+c_{B}^{n} \xi_{B, t}
\end{aligned}
$$

where $c_{A}^{*}, c_{G}^{*}, c_{A}^{n}$ and $c_{G}^{n}$ are as given in (40)-(43), and

$$
\begin{aligned}
c_{B}^{*} & \equiv \frac{1}{\sigma^{-1}(1-\Gamma)-\zeta \Gamma+\phi-1} \frac{\phi(1-\bar{B}) \bar{N}\left[(1-\bar{N})^{2} \bar{B}-\bar{N}^{2}\right]}{\left[\sigma^{-1}-\ln (\bar{B}) \bar{N} \phi-\delta\right][(1-\bar{B}) \bar{N}+\bar{B}]^{2}} \\
c_{B}^{n} & \equiv \frac{1}{\sigma^{-1}-\delta+\phi-1} \frac{(1-\bar{N}) \bar{B}}{\bar{N}+(1-\bar{N}) \bar{B}}
\end{aligned}
$$

It follows from equations (25) and (28) that $c_{B}^{n}>0$ and $c_{B}^{*}<0$. Hence $B_{t}$ is a negative cost-push shock.

Proposition 7. The insurance shock, $B_{t}$, is a negative cost-push shock:

$$
c_{B}^{u}<0
$$

$* * *$ Figure 5 is around here.***

The intuition of this result is simple. A higher $B_{t}$ reduces the efficient level of output, $Y_{t}^{*}$, because it reduces the inequality between the employed and the unemployed and hence raises the efficient rate of unemployment. On the other hand, an increase in $B_{t}$ raises the natural rate of output, $Y_{t}^{n}$, because it reduces the consumption of the employed, $C_{t}^{e}$, and hence reduces the marginal rate of substitution between leisure and consumption of the employed (and the wage rate), which raises the level of output in the flexible-price equilibrium. Figure 5 plots the optimal responses to a negative insurance shock at date $0: B_{0}=0.65$ and $B_{t}=0.75$ for $t \neq 0$. It shows that in response to such a shock, the optimal polity raises both inflation and output significantly.

\subsection{Optimal responses with cyclical $B_{t}$}

Now let us examine quantitatively how cyclical fluctuations in $B_{t}$ affects the optimal policy. Specifically, we shall consider the impulse responses of the optimal policy to a decline in $A_{t}$ or $G_{t}$, assuming that such negative shocks to the economy accompany a decrease in $B_{t}$ (an increase in the earning loss of the unemployed).

We consider the same size of the initial innovations to the productivity and government-purchase shock as in the previous figures: $\epsilon_{A, 0}=-2.34 \%$ and $\epsilon_{G, 0}=-13.76 \%$. Also, the steady-state level of risk sharing is given by $\bar{B}=0.75$ and that shocks are serially uncorrelated: $\rho_{A}=\rho_{G}=0$. Here, however, we assume that those negative shocks arrive with a temporary decline in the degree of 
risk sharing: $B_{0}=0.65$. It returns to the steady state level after one period: $B_{t}=\bar{B}$ for $t \geq 1$. Note that such a decline in $B_{t}$ (from $\bar{B}=0.75$ to $B_{0}=0.65$ ) seems to be empirically plausible. For instance, based on various empirical work, Krebs (2007) assumes that the difference in the earnings losses of displaced workers between booms and recessions is 12 percent in his numerical analysis.

***Figures 6-7 are around here. ${ }^{* * *}$

In Figures 6-7, the solid lines describe the impulse response functions of the optimal policy for those composite shocks. For comparison, the dotted lines show the case with constant $B_{t}$. As we have already seen, with constant risk sharing, the optimal policy is essentially characterized as the complete price-level stabilization. For instance, when $B_{t} \equiv 0.75, \epsilon_{A, 0}=-2.34 \%$ leads to $\pi_{0}=$ -0.0063 percent. As we know from Figure 1 , even with $B_{t} \equiv 0.5, \pi_{0}=-0.011$ percent. However, if $B_{0}$ moves together with $\epsilon_{A, 0}$, then optimal policy involves much larger responses of the inflation rate: when $B_{0}=0.65=\bar{B}-0.1, \pi_{0}=0.25 \%$. Similarly, such countercyclical income losses of the unemployed imply much larger responses of the output gap, $x_{0}=\hat{Y}_{0}-\hat{Y}_{0}^{*}\left(x_{0}=0.013 \%,-0.53 \%\right.$ for $B_{0}=\bar{B}, \bar{B}-0.1$, respectively). It is also noteworthy that countercyclical idiosyncratic income shock calls for more stabilization of the actual level of output, $\hat{Y}_{t}$ : $\hat{Y}_{0}=-1.966 \%,-0.29 \%$ for $B_{0}=\bar{B}, \bar{B}-0.1$, respectively. Figure 7 illustrates that optimal responses to the governmentpurchase shock share similar properties.

We find it interesting that the actual level of output, $\hat{Y}_{t}$, is stabilized quite strongly under optimal policy when the degree of risk sharing, $B_{t}$, fluctuates cyclically. In the case where $B_{0}$ declines to 0.65 , the optimal responses of $\pi_{0}$ and $\hat{Y}_{0}$ are in similar magnitude. There are two reasons for this. First, although negative shocks $\epsilon_{A, 0}$ and $\epsilon_{G, 0}$ tend to reduce the efficient level of output, $Y_{0}^{*}$, the deterioration in risk sharing calls for stimulation of the economy and hence tends to raise the efficient level of output. These two forces offset each other so that $\hat{Y}_{0}^{*}$ is close to zero and the equilibrium level of output is stabilized under optimal policy. Second, fluctuations in the inflation rate and the output gap are larger with cyclical $B_{t}$ because its quantitative impact on the cost push shock, $u_{t}$, is large, which, in turn, is the result that a shock to risk sharing affects the efficient and natural levels of output in the opposite directions (recall that $c_{B}^{n}>0$ and $c_{B}^{*}<0$ ).

\subsection{Extension to the case with distorted steady state}

So far we have maintained the assumption that the non-stochastic steady state is efficient (Assumption 2). Here, we relax this assumption and see that our basic result extends to the case with distorted steady state. For this purpose, we choose to follow the approach taken by Khan, King and Wolman (2003), that is, linearizing the first-order conditions for the optimal policy problem (the "Ramsey" problem), rather than the linear-quadratic approach of Benigno 
and Woodford $(2003,2005)$, which we have taken so far. ${ }^{13}$

From (17), the flow utility of the household can be written as

$$
\mathcal{W}_{t}=\ln \left(C_{e, t}\right)-\left[v+\ln \left(B_{t}\right)\right] N_{t}+\ln \left(B_{t}\right)
$$

where $v$ is the marginal disutility of labor supply: $v \equiv \omega[\ln (\mathcal{H})-\ln (\mathcal{H}-h e)]$. The Ramsey problem is then formulated as

$$
\max E_{0} \sum_{t=0}^{\infty} \beta^{t}\left\{\ln \left(C_{e, t}\right)-\left(v+\ln B_{t}\right) N_{t}\right\}
$$

subject to the equilibrium conditions:

$$
\begin{aligned}
& \lambda_{t}=\frac{1}{C_{e t}}\left\{\left(1-\frac{1}{B_{t}}\right) N_{t}+\frac{1}{B_{t}}\right\} \\
& Y_{t}-G_{t}=\left[\left(1-B_{t}\right) N_{t}+B_{t}\right] C_{e, t} \\
& F_{t}=\lambda_{t} Y_{t}+E_{t} \alpha \beta \pi_{t+1}^{\theta-1} F_{t+1} \\
& K_{t}=\lambda_{t} C_{e, t} Y_{t}^{\phi} A_{t}^{-\phi}+E_{t} \alpha \beta \pi_{t+1}^{\phi \theta} K_{t+1} \\
& F_{t}\left(\frac{1-\alpha \pi_{t}^{\theta-1}}{1-\alpha}\right)^{\frac{1+(\phi-1) \theta}{1-\theta}}=\frac{\phi \theta}{(1-\tau)(\theta-1)} \frac{\chi_{\omega}}{e h} K_{t} \\
& N_{t}=\frac{1}{e h} Y_{t}^{\phi} A_{t}^{-\phi} \Delta_{t} \\
& \Delta_{t}=(1-\alpha)\left(\frac{1-\alpha \pi_{t}^{\theta-1}}{1-\alpha}\right)^{\frac{\phi \theta}{\theta-1}}+\alpha \pi_{t}^{\theta \phi} \Delta_{t-1}
\end{aligned}
$$

where $\lambda_{t}$ is the Lagrange multiplier on the flow budget constraint in the household's utility maximization problem. Here, equation (45) is the first-order condition with respect to $C_{e, t}$ in the household's utility maximization problem; (46) is the goods market clearing condition; (47)-(49) describe the profit-maximization condition under the Calvo pricing; (50) is the aggregate production technology; and (51) defines the relative-price distortion $\Delta_{t}$. Note that the policy maker here takes as given the sticky-price distortion, the efficiency-wage distortion, the imperfectness of the unemployment insurance, and the monopoly distortion. In this sense, this is the second-best problem.

$* * *$ Figure 8 is around here. ${ }^{* * *}$

We have used Dynare to solve this problem numerically. ${ }^{14}$ We conduct the same exercise as in Figure 6 except that the steady state is no longer efficient. Specifically, we set the parameter

\footnotetext{
${ }^{13}$ As shown by Benigno and Woodford $(2003,2005)$, one could obtain a quadratic approximation to the social welfare function even when the steady state is distorted. However, as argued by Angeletos (2003), the quadratic approximation obtained in such a case tends to be too complicated to interpret. For this reason, we find it better here not to pursue their approach.

${ }^{14}$ Dynare is a suite of programs for estimation and simulation of DSGE models, which was originally developed by Michel Juillard. It is available at http://www.cepremap.cnrs.fr/dynare/.
} 
values so that the natural rate of output is 90 percent of the efficient rate of output in the steady state. The solid lines in Figure 8 plot the optimal response of inflation and output to a temporary decline in the productivity that accompanies a decline in the degree of risk sharing $B_{t}\left(B_{0}=0.65\right.$ and $B_{t}=0.75$ for $t \neq 0$ as in Figure 6$)$. For comparison, the dashed lines depict the case where $B_{t}$ is constant. ${ }^{15}$ We can see that our basic results remain to hold when the steady state is distorted: the inflation rate responds much more and output is stabilized to a larger extent when the degree of risk sharing fluctuates cyclically.

\subsection{Second moment properties}

In order to further examine the effect of cyclical fluctuations in $B_{t}$ on the optimal policy, let us investigate the second-moment properties of the model. For comparison, we consider a Taylor-rule policy as well as the Ramsey (or optimal) policy. The Taylor rule we consider is given by

$$
\ln \left(R_{t}\right)=\ln (\bar{R})+\alpha_{\pi} \ln \left(\pi_{t}\right)
$$

where $R_{t}$ is the nominal interest rate. We set $\bar{R}$ so that the inflation rate is zero at the steady state. For $\alpha_{\pi}$, we follow Dittmar, Gavin and Kydland (2005) and set $\alpha_{p} i=1.5$.

Concerning the exogenous shocks, we abstract from the government-purchase shock: $\xi_{G, t}=0$ for all $t$. We assume that the productivity process follows:

$$
\ln A_{t}=\rho_{A} \ln A_{t-1}+\xi_{A, t}
$$

where $\rho_{A}=0.95$ and $\xi_{A, t}$ is i.i.d. and follows $N\left(0, \sigma_{A}^{2}\right)$. For normalization, we choose $\sigma_{A}$ so that the standard deviation of output in the model economy with the Taylor-rule policy coincides with that in the U.S. data. For the risk sharing process, $B_{t}$, we consider two cases. The first case is the one where $B_{t}$ is constant, $B_{t}=0.75$ for all $t$. The second case is the one where $B_{t}$ fluctuates cyclically. Specifically, we consider the following process for $B_{t}$ :

$$
\ln B_{t}=\left(1-\rho_{B}\right) \ln \bar{B}+\rho_{B} \ln B_{t-1}+\sigma_{B} \xi_{A, t}
$$

where $\sigma_{B}$ is set so that one percent decline in $A$ reduces $B_{t}$ from $\bar{B}=0.75$ to 0.7 , that is, $\sigma_{B}=(\ln (0.75)-\ln (0.7)) * 100=6.9$. This is roughly consistent with the exercises we have done in Figures 6-8, and seems to be in line with the value obtained in the literature.

\section{***Table 1 is around here.***}

Table 1 shows the standard deviation of $\log$ output $(\operatorname{std}(\hat{Y})$, the standard deviation of the inflation rate $(\operatorname{std}(\pi))$, the correlation coefficient of those two variables, and the autocorrelation coefficients of each variable for the U.S. data and for several versions of our model. We can see that

\footnotetext{
${ }^{15} \mathrm{As}$ in the case with efficient steady state, when the degree of risk sharing is constant, i.e., $B_{t}=\bar{B}$ for all $t$, the optimal monetary policy is roughly equivalent to the zero-inflation policy, regardless of the value of $\bar{B}$.
} 
our basic result holds here: First, regardless of whether the steady state is efficient or not, if $B_{t}$ is constant over time, the optimal policy stabilizes the price level almost completely (the standard deviation of the inflation rate is 0.01 percent for both cases). Note that the standard deviation of output under the optimal policy is greater than that under the Taylor-rule policy. Second, if $B_{t}$ fluctuates cyclically, the optimal policy allows inflation to vary significantly, and at the same time, reduces the variation in the level of output. In terms of the standard deviations of output and inflation, the Ramsey policy with cyclical $B_{t}$ seems to generate statistics closer to the data than the Ramsey policy with constant $B_{t}$. This is also the case with correlation: The correlation between output and inflation under optimal policy is fairly high (about 0.65 ) when $B_{t}$ is constant, but it is close to zero when $B_{t}$ is cyclical, which is consistent with the data. The autocorrelation of output is higher in the optimal policy with cyclical $B_{t}$, which is, again, consistent with the data. Overall, we can see that the optimal policy with cyclical $B_{t}$ generates statistics much closer to the U.S. data than the optimal policy with constant $B_{t}$, both in terms of standard deviations and the correlation coefficients of output and inflation. Of course, our model is too stylized to compare directly to the data, but, nevertheless, we find this result interesting.

\section{Concluding remarks}

In this paper, we have considered an efficiency-wage model with the Calvo-type sticky prices and analyzed the optimal monetary policy when the unemployment insurance is not perfect. In the standard sticky-price model, the strict zero-inflation policy becomes optimal if the zero-inflation steady state is efficient. This is because the relative-price distortion is the only distortion in such a case and such distortion can be eliminated by the strict zero-inflation policy. We have seen, however, that with imperfect unemployment insurance, the strict zero-inflation policy is no longer optimal even if the zero-inflation steady-state equilibrium is efficient. Quantitatively, though, if the level of risk sharing is constant over business cycles, the difference between the optimal policy and the strict zero-inflation policy is minimal. We have also shown, however, that if the level of risk sharing is procyclical, that is, if idiosyncratic shocks are countercyclical, as evidence suggests, the difference can be substantial. Indeed, in such a case, output must be stabilized much more compared to the case with perfect insurance.

One important limitation of our model is that idiosyncratic shocks are assumed to be purely temporary. Evidence suggests that idiosyncratic shocks are highly persistent as well as countercyclical. ${ }^{16}$ Krebs (2007) argues that the persistence as well as the countercyclicality of idiosyncratic shocks matter a lot concerning the welfare cost of business cycles. Incorporating persistent idiosyncratic shocks is an important direction of future research. ${ }^{17}$

\footnotetext{
${ }^{16}$ See, for instance, Jacobson, LaLonde and Sullivan (1993) and Storesletten, Telmer, and Yaron (2004).

${ }^{17}$ In our current framework, individuals are not allowed to participate in the asset market, and all the decisions related to savings are made by the household head. As one of the referees suggested, if we are to keep this framework, introducing persistence into idiosyncratic income shocks would be roughly equivalent to increasing the variance of idiosyncratic shocks.
} 
In addition, our labor market is very stylized and so another direction of future research is to extend our model in that respect. For instance, we have assumed that a shirker would be punished by an exogenously-given amount of wage reduction. It might be worthwhile to consider a more general contract problem with a firm and a worker. Alternatively, it may be interesting to consider other specifications to generate unemployment, such as search.

\section{Acknowledgement}

I thank the editor and three anonymous referees for very helpful comments. I have also benefitted from comments and criticisms from Kosuke Aoki, Toni Braun, Yongsung Chang, Ippei Fujiwara, Jean-Michel Grandmont, Keiichiro Kobayashi, Akihisa Shibata, Tsutomu Watanabe, and seminar participants at Hitotsubashi University, Hong Kong University of Science and Technology, Keio University, Kyoto University, Kyushu University, Seoul National University, Tohoku University, the University of Tokyo, the 2006 SED meeting at Vancouver, and the 2005 SAET meeting at Vigo. Financial support by MEXT Grants-in-Aid for Scientific Research is gratefully acknowledged.

\section{Appendix}

Cost minimization problem of a firm

The first-order conditions for the cost minimization problem (8) are

$$
\begin{gathered}
\frac{e^{\prime}(W) W}{e}=1, \\
A f(e h n)=y .
\end{gathered}
$$

The first equation implies that $C_{s} / C_{e}=\tilde{s} \in[s, 1]$, where $\tilde{s}$ is defined as the solution to

$$
d(\chi-s)(1-\tilde{s})=\omega(1-s) \tilde{s}\left(\tilde{s}^{-\frac{d}{\omega}}-1\right) .
$$

Then the cost-minimizing level of effort is given by

$$
e=\frac{\mathcal{H}}{h}-\frac{\mathcal{H}}{h} \tilde{s}^{\frac{d}{\omega}} .
$$

The real wage rate is

$$
\frac{W_{t}}{P_{t}}=\frac{\chi}{h} C_{e, t}, \quad \text { where } \quad \chi \equiv \frac{1-\tilde{s}}{1-s} .
$$

Equivalence with a version of Shapiro and Stiglitz's (1984) model

Consider the following version of Shapiro and Stiglitz's (1984) model: if a shirker gets caught she is immediately fired and receives no wages; there are two levels of effort $e_{t} \in\{0, \bar{e}\}$. The rest is the same as our model in text. Then the incentive compatibility constraint becomes

$$
\mathcal{U}\left(C_{e, t}, \bar{e}\right) \geq(1-d) \mathcal{U}\left(C_{e, t}, 0\right)+d \mathcal{U}\left(C_{u, t}, 0\right)
$$


where $C_{e, t}$ and $C_{u, t}$ are as given in (4) and (6), respectively. This model and our model become essentially identical if (i) $\bar{e}$ is at the level given by (52) and (ii) the unemployment insurance program is given by

$$
\mathrm{UI}_{t}^{f}=\left(1-N_{t}\right) \operatorname{sh} W_{t}, \quad \text { and } \quad \mathrm{UI}_{t}^{b}=N_{t} \operatorname{sh} W_{t} .
$$

This is because this insurance program implies $C_{s, t}=C_{u, t}$ in our original model.

Derivation of (25) and (28)

To derive inequality (25), note that

$$
\frac{\partial Y^{*}}{\partial \bar{B}}=-\frac{Z_{Y B}}{U_{Y Y}+Z_{Y Y}-V_{Y Y}}
$$

The numeraire is negative, $U_{Y Y}+Z_{Y Y}-V_{Y Y}<0$, because of Assumption 1. The denominator is also negative:

$$
\begin{aligned}
Z_{Y B} & =-\frac{N_{Y}}{B}+\frac{N_{Y}}{N+(1-N) B}+\frac{(1-B)(1-N) N_{Y}}{[N+(1-N) B]^{2}} \\
& =\frac{(1-B) N_{Y}}{B[N+(1-N) B]} \frac{B(1-N)^{2}-N^{2}}{N+(1-N) B} \leq 0
\end{aligned}
$$

where the last inequality follows from the assumption that $N>1 / 2$.

For $(28), d \ln Y_{t}^{n} / d \ln \bar{B}$ is easier to compute:

$$
\frac{\partial \ln Y^{n}}{\partial \ln \bar{B}}=\frac{1}{\sigma^{-1}-\delta+\phi-1} \frac{(1-N) \bar{B}}{N+(1-N) \bar{B}} \geq 0
$$

Here, note that $\sigma^{-1} \geq 1$ and $\phi \geq \delta$.

Derivation of the aggregate-supply relation (32)

A log-linear approximation of the first-order condition for $p_{t}^{*},(13)$, is given by

$$
E_{t} \sum_{T=t}^{\infty}(\alpha \beta)^{T-t}\left\{\hat{p}_{t}^{*}-\hat{s}_{t, T}-\sum_{\tau=t+1}^{T} \pi_{\tau}\right\}=0
$$

where $\hat{p}_{t}^{*} \equiv \ln p_{t}^{*}-\ln P_{t}$.

The real marginal cost of firm $i$ is written as

$$
\hat{s}_{t}(i)=(\phi-1) \hat{y}_{t}(i)+\left(\sigma^{-1}-\delta\right) \hat{Y}_{t}-\left(\sigma^{-1}-\delta+\phi-1\right) \hat{Y}_{t}^{n}
$$

Taking the average over $i \in[0,1]$, the average real marginal cost in period $t$ is

$$
\hat{s}_{t}=\left(\sigma^{-1}-\delta+\phi-1\right)\left(\hat{Y}_{t}-\hat{Y}_{t}^{n}\right)
$$

Log-linearizing the demand function (10) yields

$$
\hat{y}_{t}(i)=\hat{Y}_{t}-\theta\left[\ln p_{t}(i)-\ln P_{t}\right]
$$


It follows that

$$
\begin{aligned}
\hat{s}_{t, T} & =\hat{s}_{T}+(\phi-1)\left(\hat{y}_{t, T}-\hat{Y}_{T}\right) \\
& =\hat{s}_{T}-(\phi-1) \theta \hat{p}_{t}^{*}+(\phi-1) \theta \sum_{\tau=t+1}^{T} \pi_{\tau}
\end{aligned}
$$

Substituting this into (53) yields

$$
E_{t} \sum_{T=t}^{\infty}(\alpha \beta)^{T-t}\left\{[1+(\phi-1) \theta] \hat{p}_{t}^{*}-\hat{s}_{T}+[1+(\phi-1) \theta] \sum_{\tau=t+1}^{T} \pi_{\tau}\right\}=0
$$

Solving for $\hat{p}_{t}^{*}$ and writing it in a recursive form, we obtain

$$
\hat{p}_{t}^{*}=\frac{1-\alpha \beta}{1+(\phi-1) \theta} \hat{s}_{t}+\alpha \beta E_{t} \pi_{t+1}+\alpha \beta E_{t} \hat{p}_{t+1}^{*}
$$

Log-linearizing the evolution of $P_{t},(29)$, leads to

$$
\pi_{t}=\frac{1-\alpha}{\alpha} \hat{p}_{t}^{*}
$$

Using this, (54) is rewritten as

$$
\begin{aligned}
\pi_{t} & =\frac{1-\alpha}{\alpha} \frac{1-\alpha \beta}{1+(\phi-1) \theta} \hat{s}_{t}+\beta E_{t} \pi_{t+1} \\
& =\frac{1-\alpha}{\alpha} \frac{1-\alpha \beta}{1+(\phi-1) \theta}\left(\sigma^{-1}-\delta+\phi-1\right)\left(\hat{Y}_{t}-\hat{Y}_{t}^{n}\right)+\beta E_{t} \pi_{t+1}
\end{aligned}
$$

which is equation (32) in the main text.

Derivation of the welfare approximation (33)

Remember that the household's flow utility is given by

$$
\mathcal{W}\left(Y_{t}, \Delta_{t} ; \xi_{t}\right)=U\left(Y_{t} ; G_{t}\right)+Z\left(Y_{t}, \Delta ; A_{t}, B_{t}\right)-V\left(Y_{t}, \Delta_{t} ; A_{t}\right)+\ln (\mathcal{H})
$$

where $U, Z$, and $V$ are as defined in (21)-(23). We follow Woodford (2003), and Benigno and Woodford $(2003,2005)$ to obtain a quadratic approximation of the household welfare.

We denote by $\Xi$ the vector of expansion parameters: $\Xi=\left(\hat{Y}, \xi, \Delta_{-1}^{1 / 2}\right)$. First, $U\left(Y_{t} ; G_{t}\right)$ is approximated as

$$
\begin{aligned}
U\left(Y_{t} ; G_{t}\right) & =\bar{U}+U_{Y} \tilde{Y}_{t}-U_{Y} \tilde{G}_{t}+\frac{1}{2} U_{Y Y} \tilde{Y}_{t}^{2}-U_{Y Y} \tilde{Y}_{t} \tilde{G}_{t}+\frac{1}{2} U_{Y Y} \tilde{G}_{t}^{2}+\mathcal{O}\left(\|\Xi\|^{3}\right) \\
& =U_{Y} \bar{Y}\left(\hat{Y}_{t}+\frac{1}{2} \hat{Y}_{t}\right)+\frac{1}{2} U_{Y Y} \bar{Y}^{2} \hat{Y}_{t}^{2}-U_{Y Y} \bar{Y} \bar{G} \xi G, t \hat{Y}_{t}+\text { t.i.p. }+\mathcal{O}\left(\|\Xi\|^{3}\right) \\
& =U_{Y} \bar{Y} \hat{Y}_{t}+\frac{1}{2}\left(U_{Y} \bar{Y}+U_{Y Y} \bar{Y}^{2}\right) \hat{Y}_{t}^{2}-U_{Y Y} \bar{Y}^{2} g_{t} \hat{Y}_{t}+\text { t.i.p. }+\mathcal{O}\left(\|\Xi\|^{3}\right)
\end{aligned}
$$

where $g_{t}$ measures the change in $Y_{t}$ required to keep $U_{Y}$ constant:

$$
g_{t} \equiv-\frac{U_{Y G} \bar{G}}{U_{Y Y} \bar{Y}}=s_{G} \xi_{G, t}
$$


Next, note that the evolution of $\Delta_{t},(31)$, implies that

$$
\hat{\Delta}_{t}=\alpha \hat{\Delta}_{t-1}+\frac{\alpha}{1-\alpha} \theta \phi[1+(\phi-1) \theta] \frac{\pi_{t}^{2}}{2}+\mathcal{O}\left(\|\Xi\|^{3}\right)
$$

It follows that

$$
\sum_{t=0}^{\infty} \beta^{t} \hat{\Delta}_{t}=\frac{\alpha \theta \phi[1+(\phi-1) \theta]}{(1-\alpha)(1-\alpha \beta)} \sum_{t=0}^{\infty} \beta^{t} \frac{\pi_{t}^{2}}{2}+\text { t.i.p. }+\mathcal{O}\left(\|\Xi\|^{3}\right)
$$

Then $Z\left(Y_{t}, \Delta_{t} ; A_{t}, B_{t}\right)$ and $V\left(Y_{t}, \Delta_{t} ; A_{t}\right)$ are approximated as

$$
\begin{aligned}
Z\left(Y_{t}, \Delta_{t} ; A_{t}, B_{t}\right) & =\frac{Z_{Y} \bar{Y}}{\phi} \hat{\Delta}_{t}+Z_{Y} \bar{Y} \hat{Y}_{t}+\frac{1}{2}\left(Z_{Y} \bar{Y}+Z_{Y Y} \bar{Y}^{2}\right) \hat{Y}_{t}^{2}-Z_{Y Y} \bar{Y}^{2} k_{t} \hat{Y}_{t}+\text { t.i.p. }+\mathcal{O}\left(\|\Xi\|^{3}\right) \\
V\left(Y_{t}, \Delta_{t} ; A_{t}\right) & =\frac{V_{Y} \bar{Y}}{\phi} \hat{\Delta}_{t}+V_{Y} \bar{Y} \hat{Y}_{t}+\frac{1}{2}\left(V_{Y} \bar{Y}+V_{Y Y} \bar{Y}^{2}\right) \hat{Y}_{t}^{2}-V_{Y Y} \bar{Y}^{2} q_{t} \hat{Y}_{t}+\text { t.i.p. }+\mathcal{O}\left(\|\Xi\|^{3}\right)
\end{aligned}
$$

where $k_{t}$ and $q_{t}$ are the change in $Y_{t}$ required to keep $Z_{Y}$ and $V_{Y}$ constant, respectively:

$$
\begin{aligned}
k_{t} & \equiv \frac{Z_{Y A} \bar{A}}{Z_{Y Y} \bar{Y}} \xi_{A, t}-\frac{Z_{Y B} \bar{B}}{Z_{Y Y} \bar{Y}} \xi_{B, t} \\
q_{t} & \equiv-\frac{V_{Y A} \bar{A}}{V_{Y Y} \bar{Y}} \xi_{A, t}
\end{aligned}
$$

Since the zero-inflation steady-state is conditionally efficient,

$$
U_{Y}+Z_{Y}-V_{Y}=0
$$

Note also that

$$
\hat{Y}_{t}^{*}=\frac{1}{U_{Y Y}+Z_{Y Y}-V_{Y Y}}\left(U_{Y Y} g_{t}+Z_{Y Y} k_{t}-V_{Y Y} q_{t}\right)
$$

It follows that

$$
\begin{aligned}
\mathcal{W}\left(Y_{t}, \Delta_{t} ; \xi_{t}\right)= & -\frac{U_{Y} \bar{Y}}{\phi} \hat{\Delta}_{t}+\frac{1}{2} \bar{Y}^{2}\left(U_{Y Y}+Z_{Y Y}-V_{Y Y}\right)\left(\hat{Y}_{t}-\hat{Y}_{t}^{*}\right)^{2}+\text { t.i.p. }+\mathcal{O}\left(\|\Xi\|^{3}\right) \\
=- & V_{Y} \bar{Y}\left\{\frac{1-\Gamma}{\phi} \hat{\Delta}_{t}+\frac{1}{2}\left[\sigma^{-1}(1-\Gamma)-\zeta \Gamma+\phi-1\right]\left(\hat{Y}_{t}-\hat{Y}_{t}^{*}\right)^{2}\right\} \\
& \quad+\text { t.i.p. }+\mathcal{O}\left(\|\Xi\|^{3}\right)
\end{aligned}
$$

where $\Gamma$ is defined by

$$
\Gamma \equiv \frac{Z_{Y} \bar{Y}}{U_{Y} \bar{Y}+Z_{Y} \bar{Y}}
$$

Finally, using (55), we obtain

$$
\begin{aligned}
E_{0} \sum_{t=0}^{\infty} \beta^{t} \mathcal{W}_{t}=- & \bar{Y} V_{Y} E_{0} \sum_{t=0}^{\infty} \frac{1}{2} \beta^{t} \\
& \times\left\{\frac{\alpha \theta[1+(\phi-1) \theta]}{(1-\alpha)(1-\alpha \beta)}(1-\Gamma) \pi_{t}^{2}+\left[\sigma^{-1}(1-\Gamma)-\zeta \Gamma+\phi-1\right]\left(\hat{Y}_{t}-\hat{Y}_{t}^{*}\right)^{2}\right\} \\
& + \text { t.i.p. }+\mathcal{O}\left(\|\Xi\|^{3}\right)
\end{aligned}
$$

which is (33) in the main text. 


\section{Proof of Proposition 3}

For the first part,

$$
\begin{aligned}
\left.c_{G}^{*}\right|_{B<1}-\left.c_{G}^{*}\right|_{B=1} & =\frac{\sigma^{-1}(1-\Gamma) s_{G}}{\sigma^{-1}(1-\Gamma)-\zeta \Gamma+\phi-1}-\frac{\sigma^{-1} s_{G}}{\sigma^{-1}+\phi-1} \\
& =\frac{\sigma^{-1} s_{G} \Gamma(\zeta+1-\phi)}{\left[\sigma^{-1}(1-\Gamma)-\zeta \Gamma+\phi-1\right]\left[\sigma^{-1}+\phi-1\right]}>0
\end{aligned}
$$

because

$$
\zeta+1-\phi=\frac{\delta^{2}}{Z_{Y} \bar{Y}}>0
$$

For the second part, note that

$$
\left.c_{G}^{n}\right|_{B<1}-\left.c_{G}^{n}\right|_{B=1}=\frac{\sigma^{-1} s_{G}}{\sigma^{-1}-\delta+\phi-1}-\frac{\sigma^{-1} s_{G}}{\sigma^{-1}+\phi-1}>0
$$

because $\delta>0$.

\section{Proof of Proposition 4}

For the first part, note that

$$
\begin{aligned}
\left.c_{A}^{*}\right|_{B<1}-\left.c_{A}^{*}\right|_{B=1} & =\frac{\phi-\Gamma(\zeta+1)}{\sigma^{-1}(1-\Gamma)-\zeta \Gamma+\phi-1}-\frac{\phi}{\sigma^{-1}+\phi-1} \\
& =-\frac{\left(\sigma^{-1}-1\right)(\zeta+1) \Gamma}{\left[\sigma^{-1}(1-\Gamma)-\zeta \Gamma+\phi-1\right]\left[\sigma^{-1}+\phi-1\right]}<0
\end{aligned}
$$

because $\sigma^{-1} \equiv 1 /\left(1-s_{G}\right)>1$ as long as $s_{G}>0$. The second part follows from:

$$
\begin{aligned}
\left.c_{A}^{n}\right|_{B<1}-\left.c_{A}^{n}\right|_{B=1} & =\frac{\phi-\delta}{\sigma^{-1}-\delta+\phi-1}-\frac{\phi}{\sigma^{-1}+\phi-1} \\
& =-\frac{\left(\sigma^{-1}-1\right) \delta}{\left[\sigma^{-1}-\delta+\phi-1\right]\left[\sigma^{-1}+\phi-1\right]}<0,
\end{aligned}
$$

again, because $\sigma^{-1}>1$.

\section{Proof of Lemma 1}

Lemma 1 follows from

$$
\begin{aligned}
\sigma^{-1}(1-\Gamma)+\zeta \Gamma-\left(\sigma^{-1}-\delta\right) & =\delta-\Gamma\left(\sigma^{-1}+\zeta\right) \\
& =\delta-\frac{Z_{Y} Y}{Z_{Y} Y+\sigma^{-1}}\left\{\sigma^{-1}+\frac{\delta^{2}}{Z_{Y} Y}+\phi-1\right\} \\
& =\frac{1}{Z_{Y} Y+\sigma^{-1}}\left\{\left(\sigma^{-1}-\delta\right)[2 \delta+\ln (B) N \phi]-(\phi-1)[-\ln (B) N \phi-\delta]\right\}
\end{aligned}
$$




\section{Proof of Proposition 5}

That $c_{G}^{u}<0$ follows from

$$
\begin{aligned}
c_{G}^{u} & =c_{G}^{*}-c_{G}^{n} \\
& =\frac{\sigma^{-1}(1-\Gamma) s_{G}}{\sigma^{-1}(1-\Gamma)-\zeta \Gamma+\phi-1}-\frac{\sigma^{-1} s_{G}}{\sigma^{-1}-\delta+\phi-1}<0
\end{aligned}
$$

because $\Gamma>0$ and $\sigma^{-1}(1-\Gamma)-\zeta \Gamma>\sigma^{-1}-\delta$ under condition (44). The second inequality, $c_{A}^{u}>0$, is derived as:

$$
\begin{aligned}
c_{A}^{u} & =c_{A}^{*}-c_{A}^{n} \\
& =\frac{\phi-\Gamma \zeta-\Gamma}{\sigma^{-1}(1-\Gamma)-\zeta \Gamma+\phi-1}-\frac{\phi-\delta}{\sigma^{-1}-\delta+\phi-1} \\
& =\frac{\left(\sigma^{-1}-1\right)[(1-\Gamma) \delta+\Gamma(\phi-1-\zeta)]}{\left[\sigma^{-1}(1-\Gamma)-\zeta \Gamma+\phi-1\right]\left[\sigma^{-1}-\delta+\phi-1\right]}
\end{aligned}
$$

Remember that

$$
\zeta=\phi-1+\frac{\delta^{2}}{Z_{Y} Y}, \quad \text { and } \quad \Gamma=\frac{Z_{Y} Y}{Z_{Y} Y+\sigma^{-1}}
$$

Thus

$$
(1-\Gamma) \delta+\Gamma(\phi-1-\zeta)=\frac{\delta}{Z_{Y} Y}\left(\sigma^{-1}-\delta\right)
$$

We finally obtain

$$
c_{A}^{u}=\frac{\left(\sigma^{-1}-1\right)\left(\sigma^{-1}-\delta\right) \delta}{\left[\sigma^{-1}(1-\Gamma)-\zeta \Gamma+\phi-1\right]\left[\sigma^{-1}-\delta+\phi-1\right] Z_{Y} Y}>0
$$

because $\sigma^{-1}>1$ because $s_{G}>0$ and $\sigma^{-1}>\delta$ because of (44).

\section{Proof of Proposition 6}

Define the quadratic function $f(\mu)$ by

$$
f(m) \equiv \beta m^{2}-\left(1+\beta+\kappa^{2} \frac{q_{\pi}}{q_{y}}\right) m+1
$$

Then $f(m)=0$ has two roots: $\mu \in(0,1)$ and $(\beta \mu)^{-1}>1$. Remember that

$$
\begin{aligned}
\kappa & =\frac{1-\alpha}{\alpha} \frac{1-\alpha \beta}{1+\theta(\phi-1)}\left(\sigma^{-1}-\delta+\phi-1\right) \\
q_{\pi} & =\frac{\alpha \theta[1+\theta(\phi-1)]}{(1-\alpha)(1-\alpha \beta)}(1-\Gamma) \\
q_{y} & =\sigma^{-1}(1-\Gamma)-\zeta \Gamma+\phi-1
\end{aligned}
$$

It follows that

$$
\kappa^{2} \frac{q_{\pi}}{q_{y}}=\theta \frac{(1-\alpha)(1-\alpha \beta)}{\alpha[1+\theta(\phi-1)]} \frac{(1-\Gamma)\left(\sigma^{-1}-\delta+\phi-1\right)^{2}}{\sigma^{-1}(1-\Gamma)-\zeta \Gamma+\phi-1}
$$


For $\left.\mu\right|_{\bar{B}<1}>\left.\mu\right|_{\bar{B}=1}$, it suffices to show that

$$
\frac{(1-\Gamma)\left(\sigma^{-1}-\delta+\phi-1\right)^{2}}{\sigma^{-1}(1-\Gamma)-\zeta \Gamma+\phi-1}<\sigma^{-1}+\phi-1
$$

Under our assumption,

$$
\sigma^{-1}-\delta+\phi-1<\sigma^{-1}(1-\Gamma)-\zeta \Gamma+\phi-1
$$

It then follows that

$$
\begin{aligned}
\frac{(1-\Gamma)\left(\sigma^{-1}-\delta+\phi-1\right)^{2}}{\sigma^{-1}(1-\Gamma)-\zeta \Gamma+\phi-1} & <\sigma^{-1}-\delta+\phi-1 \\
& <\sigma^{-1}+\phi-1
\end{aligned}
$$




\section{References}

[1] Alexopoulos, M., 2004. Unemployment and the business cycle. Journal of Monetary Economics $51,277-298$.

[2] Angeletos, G.M., 2003. Comments. NBER Macroeconomics Annual 18, 350-361.

[3] Benigno, P., Woodford, M., 2003. Optimal monetary and fiscal policy: A linear-quadratic approach. NBER Macroeconomics Annual 18, 271-333.

[4] Benigno, P., Woodford, M., 2005. Inflation stabilization and welfare: The case of a distorted steady state. Mimeo.

[5] Calvo, G., 1983. Staggered prices in a utility-maximizing framework. Journal of Monetary Economics 12, 383-398.

[6] Christiano, L.J., Eichenbaum, M., Evans, C.L., 2005. Nominal rigidities and the dynamic effects of a shock to monetary policy. Journal of Political Economy 113, 1-45.

[7] Dittmar, R.D., Gavin, W.T., Kydland, F.E., 2005 Inflation persistence and flexible prices. International Economic Review 46, 245-261.

[8] Goodfriend, M., King, R.G., 1997. The new neoclassical synthesis and the role of monetary policy. NBER Macroeconomics Annual, 12, 231-283.

[9] Gruber, J., 1997. The consumption smoothing benefits of unemployment insurance. American Economic Review 87, 192-205.

[10] Hagedorn, M., Manovskii, I., 2008. The cyclical behavior of equilibrium unemployment and vacancies revisited. American Economic Review 98, 1692-1706.

[11] Hansen, G.D., 1985. Indivisible labor and the business cycle. Journal of Monetary Economics $16,309-327$.

[12] Jacobson, L.S., LaLonde, R.J., Sullivan, D.G., 1993. Earning losses of displaced workers. American Economic Review 83, 685-709.

[13] Khan, A., King, R.G., and Wolman, A.L., 2003. Optimal monetary policy. Review of Economic Studies 70, 825-860.

[14] Krebs, T., 2007. Job displacement risk and the cost of business cycles. American Economic Review 97, 664-686.

[15] Rogerson, R., 1988. Indivisible labor, lotteries, and equilibrium. Journal of Monetary Economics 21, 1-16.

[16] Rotemberg, J.J., Woodford, M., 1997. An optimization-based econometridc framework for the evaluation of monetary policy. NBER Macroeconomics Annual 12, 297-346. 
[17] Schmitt-Grohé, S., Uribe, M., 2005. Optimal fiscal and monetary policy in a medium-scale macroeconomic model: Expanded version. NBER Working Paper 11417.

[18] Shapiro, C., Stiglitz, J.E., 1984. Equilibrium unemployment as a worker discipline device. American Economic Review 74, 433-444.

[19] Shimer, R., 2005. The cyclical behavior of equilibrium unemployment and vacancies. American Economic Review 95, 25-49.

[20] Storesletten, K., Telmer, C.I., Yaron, A., 2004. Cyclical dynamics in idiosyncratic labor marke risk. Journal of Political Economy 112, 695-717.

[21] Woodford, M., 1995. Price-level determination without control of a monetary aggregate. Carnegie-Rochester Conference Series on Public Policy 43, 1-46.

[22] Woodford, M., 2003. Interest and prices: Foundations of a theory of monetary policy. Princeton University Press, Princeton.

[23] Woodford, M., 2005. Firm-specific capital and the New Keynesian Phillips curve. NBER working paper 11149.

[24] Yun, T., 2005. Optimal monetary policy with relative price distortions. American Economic Review 95, 89-109. 
Table 1: Second-moment properties

(a) The case of efficient steady state

\begin{tabular}{c|c|cc|cc}
\hline \hline & & \multicolumn{2}{|c|}{ Constant $B_{t}$} & \multicolumn{2}{c}{ Cyclical $B_{t}$} \\
\cline { 3 - 6 } & Data & Taylor & Ramsey & Taylor & Ramsey \\
\hline $\operatorname{std}\left(\hat{Y}_{t}\right)$ & 1.50 & 1.50 & 1.74 & 1.50 & 1.27 \\
$\operatorname{std}\left(\pi_{t}\right)$ & 1.11 & 0.66 & 0.01 & 0.81 & 0.35 \\
$\operatorname{corr}\left(\hat{Y}_{t}, \pi_{t}\right)$ & 0.15 & -1.00 & 0.65 & -1.00 & -0.10 \\
$\operatorname{AR} 1\left(\hat{Y}_{t}\right)$ & 0.86 & 0.71 & 0.71 & 0.71 & 0.91 \\
$\operatorname{AR} 1\left(\pi_{t}\right)$ & 0.49 & 0.71 & 0.42 & 0.71 & 0.42 \\
\hline \hline
\end{tabular}

(b) The case of inefficient steady state

\begin{tabular}{c|c|cc|cc}
\hline \hline & & \multicolumn{2}{|c|}{ Constant $B_{t}$} & \multicolumn{2}{c}{ Cyclical $B_{t}$} \\
\cline { 3 - 6 } & Data & Taylor & Ramsey & Taylor & Ramsey \\
\hline $\operatorname{std}\left(\hat{Y}_{t}\right)$ & 1.50 & 1.50 & 1.76 & 1.50 & 1.38 \\
$\operatorname{std}\left(\pi_{t}\right)$ & 1.11 & 0.67 & 0.01 & 0.95 & 0.32 \\
$\operatorname{corr}\left(\hat{Y}_{t}, \pi_{t}\right)$ & 0.15 & -1.00 & 0.64 & -1.00 & -0.18 \\
$\operatorname{AR} 1\left(\hat{Y}_{t}\right)$ & 0.86 & 0.71 & 0.71 & 0.71 & 0.90 \\
$\operatorname{AR} 1\left(\pi_{t}\right)$ & 0.49 & 0.71 & 0.40 & 0.71 & 0.40 \\
\hline \hline
\end{tabular}

Notes: All series are HP filtered. The inflation rates are annual rates. The sample period of the data is 1960.I-2007.IV. 'Taylor' denotes the equilibrium under the Taylor rule, and 'Ramsey' denotes the equilibrium under the Ramsey policy. $\operatorname{std}(x)$ is the standard deviation of variable $x$; $\operatorname{corr}(x, y)$ is the correlation coefficient between variables $x$ and $y$; and $\operatorname{AR} 1(x)$ is the autocorrelation coefficient of variable $x$. 

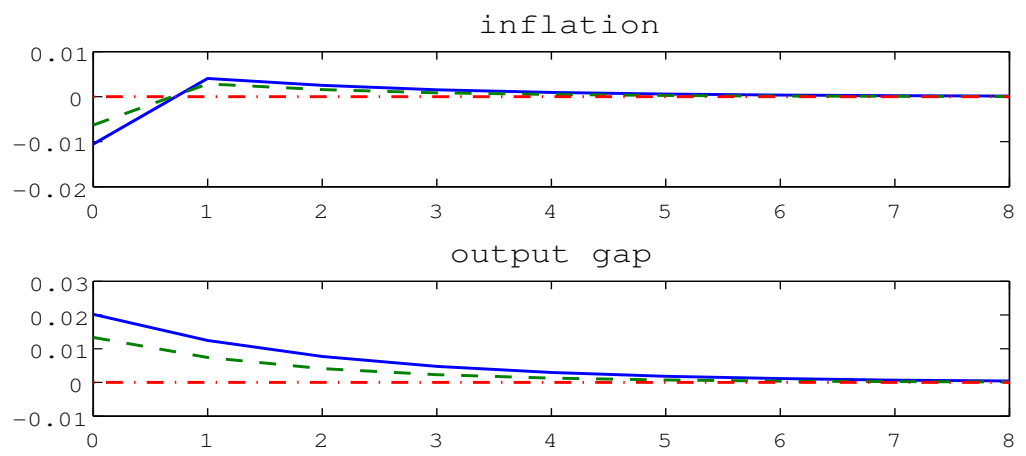

output

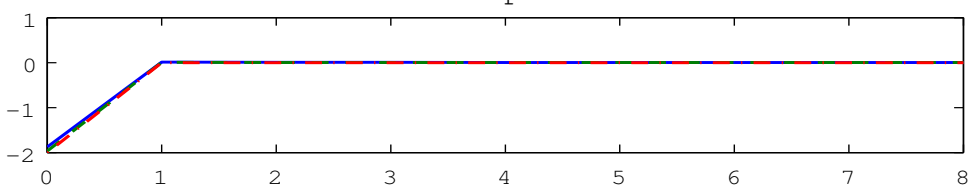

Figure 1: Optimal responses to a negative productivity shock for different degrees of risk sharing. In each panel, the solid, dashed, and dash-dotted lines correspond to $\bar{B}=0.5,0.75,1.0$, respectively. Note: The inflation rate is expressed at an annual rate in percentage points. The output gap and the level of output are expressed as percentage deviations from their respective steady-state values.
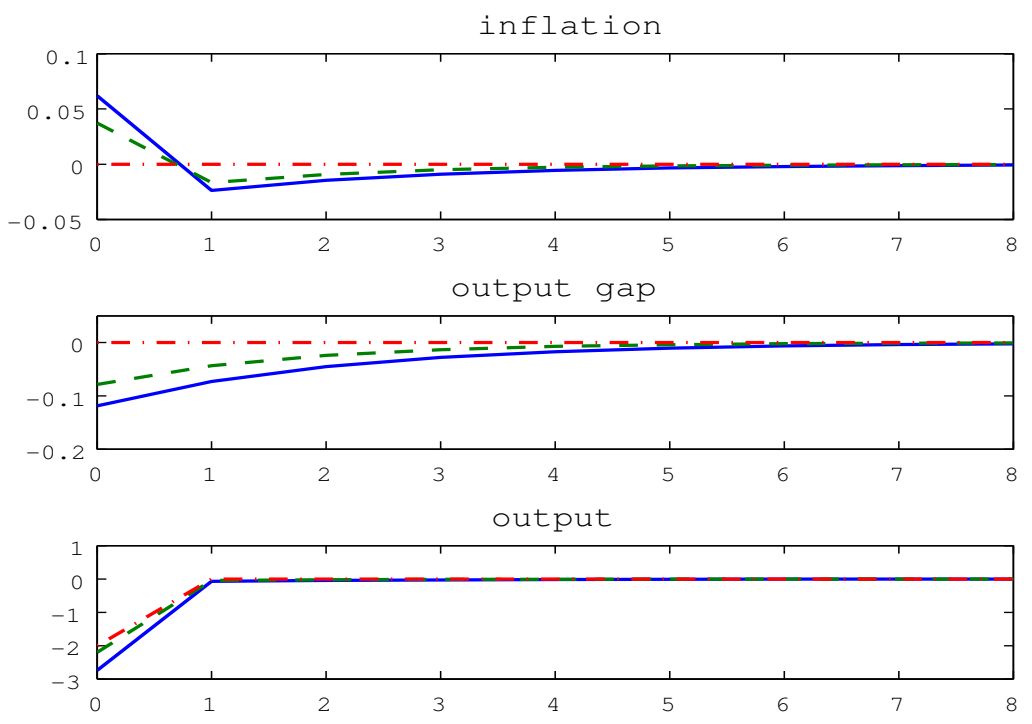

Figure 2: Optimal responses to a negative government-purchase shock for different degrees of risk sharing. In each panel, the solid, dashed, and dash-dotted lines correspond to $\bar{B}=0.5,0.75,1.0$, respectively. See the note in Figure 1 for the units. 

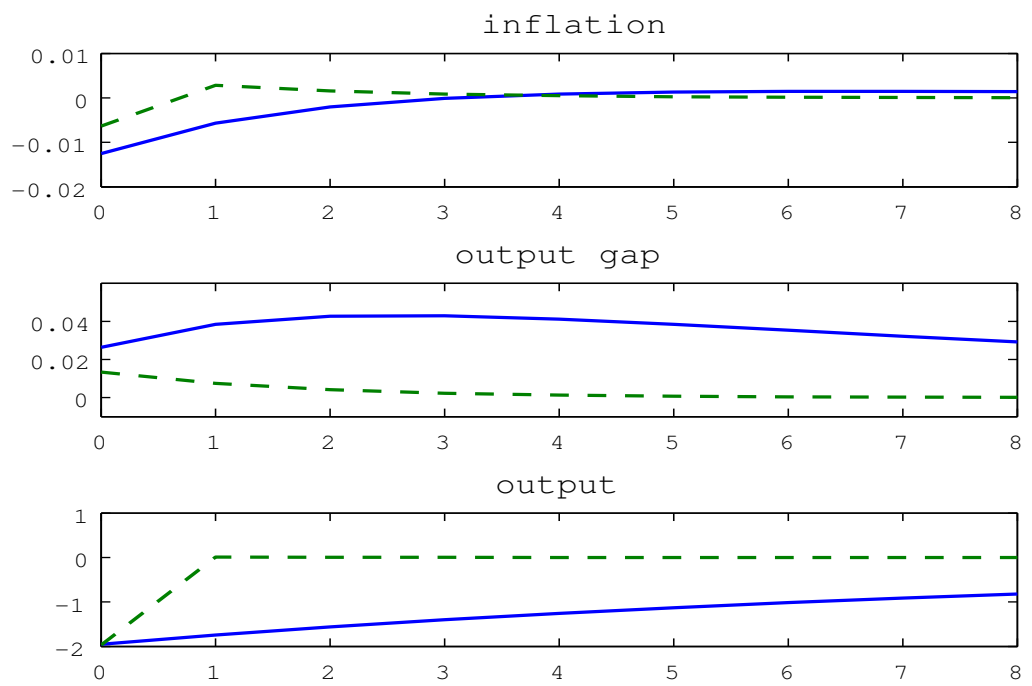

Figure 3: Optimal responses to a negative productivity shock with $\rho_{A}=0.9$ (solid line) and $\rho_{A}=0$ (dashed line). See the note in Figure 1 for the units.
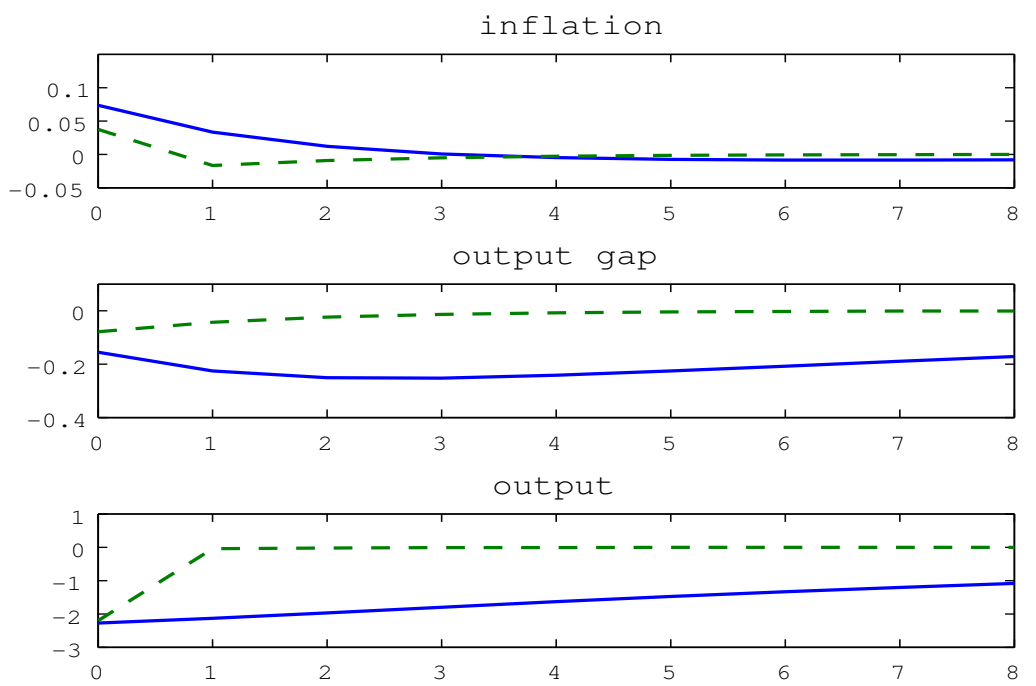

Figure 4: Optimal responses to a negative government-purchase shock with $\rho_{G}=0.9$ (solid line) and $\rho_{G}=0$ (dashed line). See the note in Figure 1 for the units. 


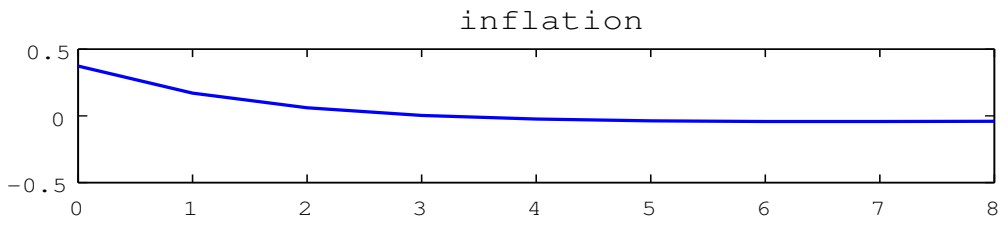

output gap

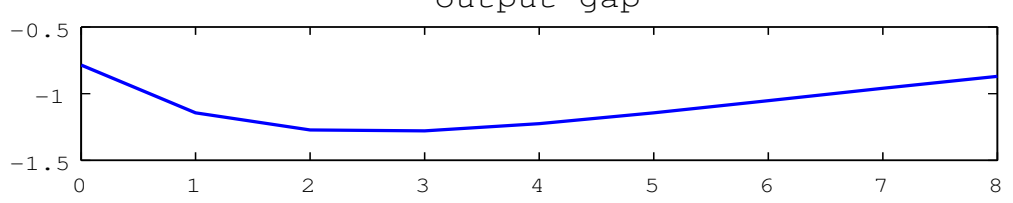

output

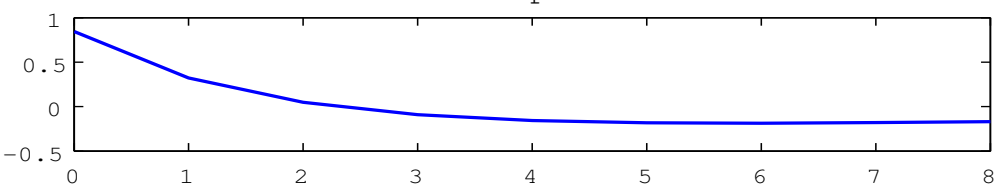

Figure 5: Optimal responses to a negative insurance shock. See the note in Figure 1 for the units.
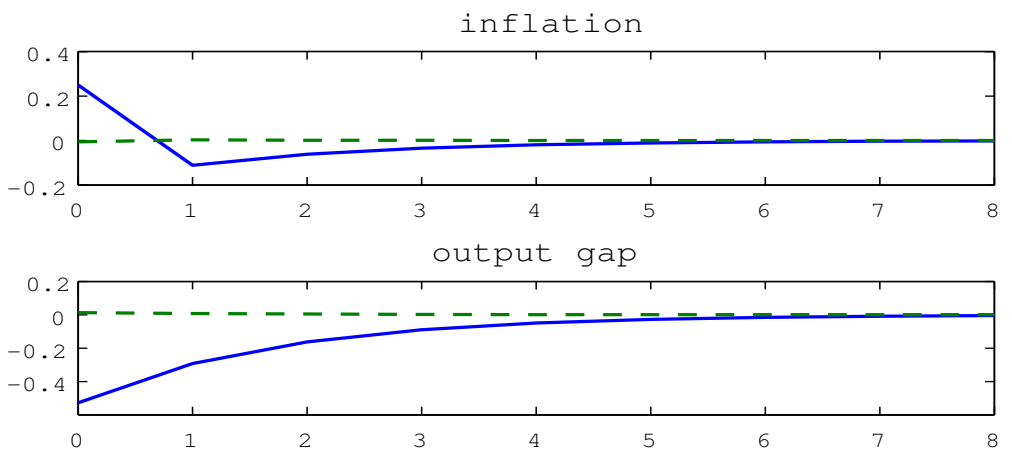

output

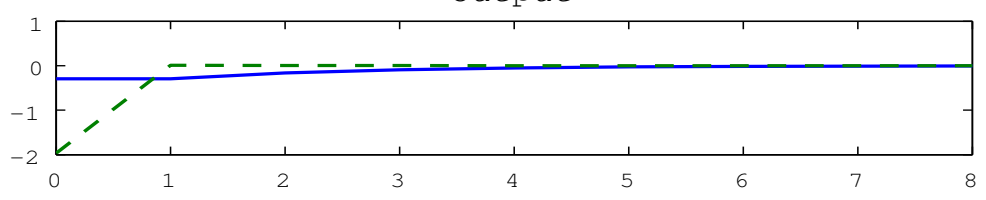

Figure 6: Optimal responses to a negative productivity shock with cyclical $B_{t}$ (solid line) and constant $B_{t}$ (dashed line). See the note in Figure 1 for the units. 

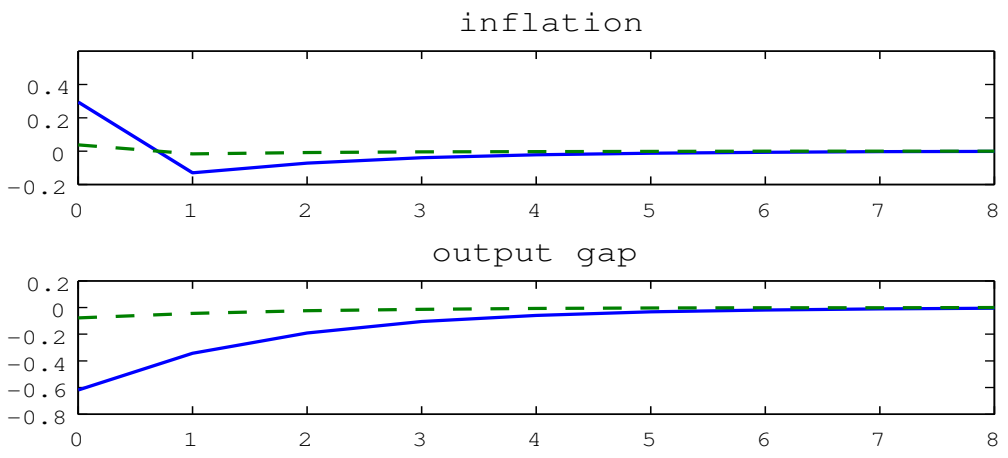

output

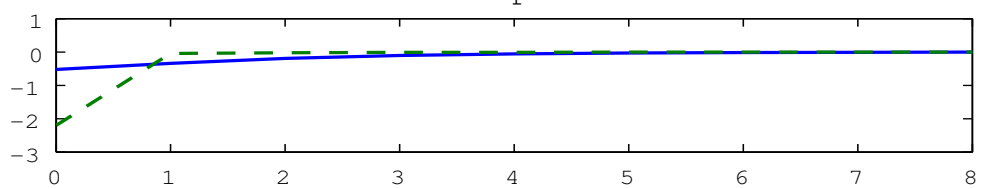

Figure 7: Optimal responses to a negative government-purchase shock with cyclical $B_{t}$ (solid line) and constant constant $B_{t}$ (dashed line). See the note in Figure 1 for the units.
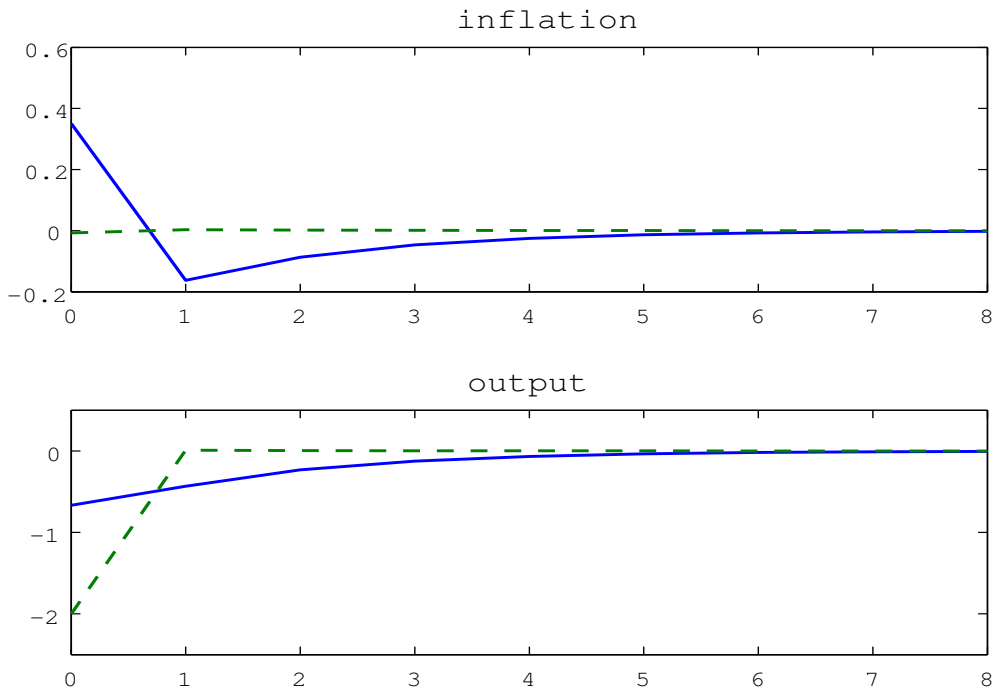

Figure 8: Optimal responses to a negative productivity shock with cyclical $B_{t}$ (solid line) and constant $B_{t}$ (dashed line) when the steady state is distorted. See the note in Figure 1 for the units. 